\title{
Making decisions with a continuous mind
}

\author{
S. SCHERbaum AND M. DShemuchadSE \\ Technische Universität Dresden, Dresden, Germany \\ AND \\ A. KALIS \\ Utrecht University, Utrecht, The Netherlands
}

\begin{abstract}
Neuroeconomics is a rapidly expanding field at the interfaces of the human sciences. The interdisciplinary nature of this field results in several challenges when attempts are made to solve puzzling questions in human decision making, such as why and how people discount future gains. We argue that an empirical approach based on dynamic systems theory (DST) could inspire and advance the neuroeconomic investigation of decisionmaking processes in three ways: by enriching the mental model, by extending the empirical tool set, and by facilitating interdisciplinary exchange. The present article addresses the challenges neuroeconomics faces by focusing on intertemporal choice. After a brief introduction of DST and related research, a DST-based conceptual model of decision making is developed and linked to underlying neural principles. On this basis, we outline the application of DST-informed empirical strategies to intertemporal choice. Finally, we discuss the general consequences of and possible objections to the proposed approach to research in intertemporal choice and the field of neuroeconomics.
\end{abstract}

Decision making, the selection of an action among several alternatives, is a central part of human behavior. Various disciplines, such as philosophy, economics, psychology, and neuroscience, have been concerned with the processes and problems involved in decision making. Over the last decade, these fields have grown together, as is apparent from the increasing number of studies in the emerging interdisciplinary field of neuroeconomics (e.g., Loewenstein, Rick, \& Cohen, 2008; cf. Sanfey, Loewenstein, McClure, \& Cohen, 2006). Neuroeconomics has enhanced both neuroscience and economics in terms of paradigms and methods. However, the interdisciplinary cooperation has resulted not only in an expansion of the scientific horizon, but also in an incorporation of the blind spots of the collaborating fields (see Glimcher, Dorris, \& Bayer, 2005).

In this article, we propose to enrich the scientific investigation of human decision making by an empirical approach based on the concepts of dynamic systems theory (DST). Although this approach is rooted in mathematics and philosophy (e.g., Ashby, 1956, 1960; van Gelder \& Port, 1995), the focus of this article is to offer empirical inspiration to researchers in the field of human decision making by a moderate DST-informed approach. DST has been applied successfully to different subfields of the above-mentioned disciplines (e.g., Juarrero, 1999; Kelso, 1995; Spivey, 2007; Thelen \& Smith, 1996; but see Grush, 1997). It can contribute to neuroeconomics on two counts. At the theoretical level, DST can form a common conceptual ground for all of the participating fields and could enable researchers to define and investigate innovative research questions. At the methodological level, a DST-informed approach can enrich the design and analysis of empirical studies. Although the methods proposed here are not new per se, the combination of these methods within a common framework provides a new perspective on human decision making.

In the following, we will outline current approaches to decision making, focusing on the field of neuroeconomics and, in particular, on intertemporal choice. Subsequently, we will briefly review current DST-informed research and will introduce the concepts of the DST perspective, their neural basis, and a theoretical model of a dynamic decision system. Next, we will build on this new mental model and will elaborate on DST-informed empirical strategies applied to intertemporal choice. We then will examine the potential benefits of the DST-informed contribution to both intertemporal choice and neuroeconomics. Finally, we will discuss the limits of the approach presented and possible objections against a DST-informed approach to decision making and to cognition in general.

\section{INTERDISCIPLINARY RESEARCH ON DECISION MAKING}

Traditionally, the various disciplines involved in the study of decision making have taken different perspectives on their topic (see Glimcher et al., 2005). 
In philosophy, the mainstream view follows the socalled belief-desire model, which originates from Hume (1739; Wallace, 1990). It essentially posits that people make decisions on the basis of their desires (on what they want) and their beliefs (concerning the way their desires could be fulfilled). Moral philosophy tries to define norms for a morally correct decision and the responsibilities of a decider (see, e.g., Audi, 2006; Hare, 1981; Scanlon, 1998).

In economics, rational decisions are traditionally considered to aim for utility maximization. For decisions under risk, like those present in most real-life situations, von Neumann and Morgenstern (1944) formulated the expected utility theory. The utility of a decision option is calculated by considering a probability-weighted average of the utilities in each possible state. Following this notion, a rational decider should always choose the decision option with the highest utility. Since such an objective choice mechanism turned out to be too simplistic to describe human behavior, it was further specified in various subjective expected utility theories (for reviews, see Fishburn, 1981; Hastie \& Dawes, 2001), the most prominent one being the prospect theory proposed by Kahneman and Tversky (1979).

In psychology, probability and value soon turned out to be insufficient to describe human decision-making behavior appropriately. The risk preference model proposed by Atkinson (1957) was a first attempt to extend the rational utility model by psychological concepts, such as motivation and emotion, and was followed by many others (e.g., Isen, 2000; Naqvi, Shiv, \& Bechara, 2006; Schwarz, 2000).

Despite large efforts within the various disciplines, most theories failed to be either sufficiently general or parsimonious (Glimcher et al., 2005). A broadly accepted theory of decision making has not emerged yet (Kahneman, 2003).

\section{Neuroeconomics}

This situation called for an interdisciplinary cooperation between the various disciplines. The first attempt to integrate decision-making research in neighboring fields was made half a century ago, with the aim of integrating empirical results from psychology into economic theories (Simon, 1965). Not until a couple of decades later was further integration undertaken: The behavioral and economic research traditions became unified with the aspiring neurosciences in the newly created field of neuroeconomics (e.g., Platt \& Glimcher, 1999).

The goal of neuroeconomics is to understand the neural basis of individual choice behavior (Sugrue, Corrado, \& Newsome, 2005) and its core processes (for more detailed reviews, see Camerer, Loewenstein, \& Prelec, 2005; Glimcher \& Rustichini, 2004; Kenning \& Plassmann, 2005; Loewenstein et al., 2008; Sanfey, 2007). With minor differences, these central processing stages are presumed to be the same for simple sensory decisions (Bogacz, 2007) and complex economic decisions (Zak, 2004). After obtaining information about the options, an evaluation process takes place, which is followed by a choice (Fellows, 2004; Zak, 2004; see Figure 1).

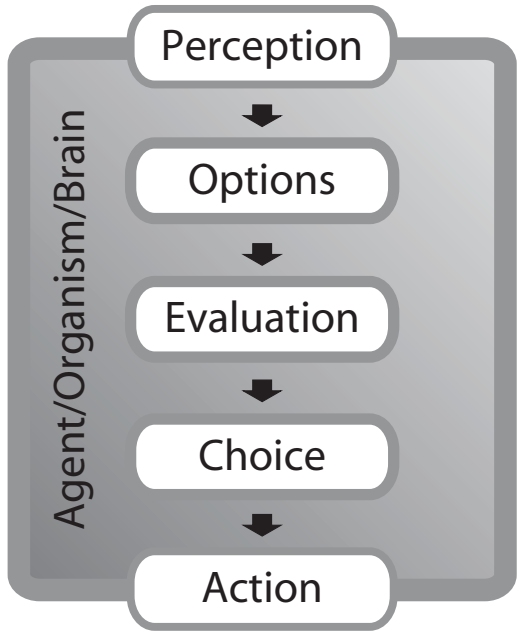

Figure 1. The core processing stages of decision making (see Fellows, 2004; Sugrue, Corrado, \& Newsome, 2005).

In identifying the neural substrate of decision making, neuroeconomics had a promising start (for a review, see Doya, 2008). Economists were hoping for better predictions of human behavior by quantitatively measuring and predicting internal variables such as value (Sugrue et al., 2005). Neuroscientists, in turn, benefited from a wide range of well-designed decision paradigms and mathematical models (Zak, 2004).

\section{Challenges for the Neuroeconomic Approach}

Sanfey (2007) has argued that neuroeconomics can prosper by using these complementary strengths. However, the divergence of the description levels used in the different disciplines apparently results in explanatory difficulties.

On the one hand, neuroscientists often use only the most basic elements of rational choice theory to explain their simple task data (e.g., Camerer et al., 2005). Yet their aim is to transfer their results from the microscopic description level (e.g., single-cell studies) of low-level perceptual choice tasks to everyday human decision making (Sanfey, 2007), as formally described by economists in complex mathematical models. This theoretical transfer is difficult, since the processing stages of the different levels have to be matched. A pragmatic solution to this problem is to draw metaphoric analogies (e.g., Sanfey et al., 2006). However, this approach is not necessarily evidently valid and has, hence, been called into question (Oullier \& Kelso, 2006).

Economists, on the other hand, apply the classical model (see Figure 1) to specific decision-making problems. Since the relation of the evaluation step to brain processes is highly undetermined (Glimcher et al., 2005), they infer, on the basis of simple correlations between brain activity and behavior, that there is a localizable decider in the brain (e.g., Camerer et al., 2005; Sugrue et al., 2005). One example is the grounding of theories of human decision making in the existence of two independent brain systems (see below for the example of intertemporal choice). In fact, the mapping of two independent systems onto dis- 
tinct brain structures is controversial, since there is little physiological evidence providing direct support (Sugrue et al., 2005). In contrast, there is accumulating evidence that decision making is a holistic process distributed over the whole brain (Glimcher et al., 2005). Thus, the question of how decisions are made remains unsolved.

In the following, we will exemplify the issues identified with the case of intertemporal choice, one of the most extensively studied topics in neuroeconomics today.

\section{An Example: Intertemporal Choice}

An intertemporal choice involves alternatives that differ not only in terms of their value, but also in their time distribution: It is about choosing between an immediate smaller gain and a delayed larger gain (for a review, see Berns, Laibson, \& Loewenstein, 2007; Frederick, Loewenstein, \& O'Donoghue, 2002; Loewenstein et al., 2008).

The original discounted utility model in economics (Samuelson, 1937) assumes that a value is discounted exponentially over time. ${ }^{1}$ This implies that a given time delay leads to the same relative value reduction, so that choosing between $\$ 10$ today and $\$ 11$ tomorrow and choosing between $\$ 10$ in 1 year and $\$ 11$ in 1 year and a day would be equivalent. Hence, a rational agent makes his choice consistently for either the short-term or the long-term option, even if the exponential discount rate is very high. In contrast to this rational choice model, people often care about the same time delay more if it is close to the present, rather than far in the future (Kirby \& Herrnstein, 1995; Rachlin $\&$ Raineri, 1992). The first part of their discount function is much steeper than an exponential function, and some have argued that it can be described better by a hyperbolic function (Ainslie, 1975). ${ }^{2}$ Alternative models propose a variety of different hyperbola-like functions (e.g., Green \& Myerson, 2004; Laibson, 1997; Loewenstein \& Prelec, 1992; Phelps \& Pollak, 1968). Green and Myerson demonstrated that adding a nonlinear scaling parameter to a hyperbolic function ${ }^{3}$ improves the fit of the data significantly more than would be expected from simply adding one free parameter. The shape of another quasihyperbolic discount function ${ }^{4}$ often utilized in neuroeconomics is also defined by two parameters (e.g., McClure, Laibson, Loewenstein, \& Cohen, 2004): $\beta$, responsible for the steep short-term decline in subjective value; and $\delta$, causing the mild long-term decline of the subjective value.

The attempts by economists to describe discounting behavior formally have been the starting point for the neuroeconomic investigation of intertemporal choice. To outline the challenges in this growing field, we will raise three issues playing a central role. First, we will present the currently dominant explanation for human discounting behavior: the two-system approach. Second, we will consider alternative explanations that link the discounting behavior to neural processes underlying time perception and reward anticipation. Third, we will highlight the diversity in the field to emphasize that further effort is needed to come up with a general theory.

The two-system approach. The existence of the two different discount parameters in descriptive models has led to the hypothesis that the human value system consists of multiple selves, with different preferences resulting in intrapersonal conflicts: a current self preferring immediate gains and a future self considering the more distant future (e.g., Fudenberg \& Levine, 2006; Thaler \& Shefrin, 1981). The separate value systems are attributed to more general brain systems: one emotional or impulsive, oriented toward the present, and the other one cognitive or rational, anticipating and caring about the distant future (e.g., Berns et al., 2007; Metcalfe \& Mischel, 1999). The first system is supposed to account for impulsiveness; the second one should enable self-control.

The distinction between the two systems will be considered here on two levels: at the neuroscientific level with respect to brain activity and at the behavioral level with respect to impulsive choice behavior.

On the neuroscientific level, a distinction between the two systems has been supported by fMRI studies on subjects making choices between immediate smaller and delayed larger amounts of money (McClure et al., 2004). During all intertemporal choices, the lateral prefrontal cortex and the posterior parietal cortex were active. However, the mesolimbic dopamine system and associated regions were involved only in choices with an immediate outcome. Accordingly, the prefrontal activations were taken to reflect an involvement of the subject's $\delta$ system, whereas the limbic activations were taken to reflect the impulsive $\beta$ system.

Although this study added weight to the two-system model of temporal discounting, the artificial conditions in which the choices were made might be criticized. ${ }^{5}$ However, other studies revealed similar discounting effects for hypothetical and real rewards (Lagorio \& Madden, 2005; Lane, Cherek, Pietras, \& Tcheremissine, 2003; Madden, Begotka, Raiff, \& Kastern, 2003), and in a second study, McClure, Ericson, Laibson, Loewenstein, and Cohen, (2007) replicated their findings, using primary rewards (juice/water). Additional support has been provided by studies directly comparing learning conditions with optimal rewards on different time scales (Tanaka et al., 2004; Tanaka et al., 2006).

Surprisingly, McClure et al. (2007) were not able to find hyperbolic discounting and activity differences in the limbic reward-related areas when the immediate option was delayed by only $10 \mathrm{~min} .{ }^{6}$ Other studies also have failed to show evidence for the activation of the impulsive system, although they have been able to confirm the relationship between cognitive processing areas and long-term thinking (Wittmann, Leland, \& Paulus, 2007; Yarkoni, Braver, Gray, \& Green, 2005). Contrary to McClure et al. (2007; McClure et al., 2004), Kable and Glimcher (2007) found that neurometric discount functions in McClure's impulsive regions matched the behavioral functions fairly well, independently of the magnitude of the delay. They concluded that the activity found in the ventral striatum, medial prefrontal cortex, and posterior cingulate cortex represents subjective value at all delays. The inconsistent findings in human studies, in combination with the lack of evidence from animal studies (for a review, see Kalenscher \& Pennartz, 2008), call into question the existence of two separate brain systems engaged in different aspects of temporal discounting. 
On the behavioral level, a distinction between the two systems is often based on clinical psychopharmacological studies, in which more severe discounting has been observed in clinical populations with a high level of impulsivity (for a review, see Chabris, Laibson, \& Schuldt, 2008; Critchfield \& Kollins, 2001; Reynolds, 2006). Nevertheless, this interpretation is not compelling, because even strong discounting could be exponential and, therefore, time consistent and rational (Becker \& Murphy, 1988). Apart from that, the main problem in connecting intertemporal choice with impulsivity arises from the lack of agreement on a definition of impulsivity and the multidimensionality of this concept (Arce \& Santisteban, 2006; Bickel \& Marsch, 2001; Evenden, 1999). Although some scientists have defined short-term thinking as being at the core of impulsivity, this tells us nothing about the generalizability to other domains of impulsive behavior. For example, temporal discounting is only weakly correlated with trait-level questionnaire assessments of impulsivity (Reynolds, Ortengren, Richards, \& de Wit, 2006) and gambling, which is another behavioral measure of impulsivity (Holt, Green, \& Myerson, 2003). In addition, frontal lobe injury, a common source of inability to control impulsive behavior, does not affect temporal discounting (Fellows $\&$ Farah, 2005). Beyond this, there is evidence that under optimal learning conditions, impulsivity can be restricted by strategic rule implementation and perfect self-control (Lane et al., 2003; Schweighofer et al., 2006).

Taken together, it seems to be difficult to find distinctive conditions for impulsive and self-controlled behavior in intertemporal choice.

Processes of time perception and reward anticipation in intertemporal choice. Alternative neuroeconomic explanations for temporal discounting and the observed inconsistencies have concentrated on two domains: time and reward.

First, discounting anomalies have been attributed to logarithmic time perception following the Weber-Fechner law (Takahashi, 2005; Takahashi, Oono, \& Radford, 2008). Furthermore, it has been demonstrated that temporal discounting can be influenced by the presentation of the delay time: The presentation of the delay as a date, instead of as an interval, evokes less discounting (Read, Frederick, Orsel, \& Rahman, 2005).

Second, the high variability of discount functions with respect to the kind of reward suggests an involvement of reward evaluation processes in intertemporal choice. For example, money is discounted to a lesser degree than food or alcohol (Odum, 2006; Odum \& Rainaud, 2003), perhaps due to visceral influences (Loewenstein, 1996). In addition, discount rates tend to be lower for higher amounts of money (Kirby, 1997) and for losses (Murphy, Vuchinich, \& Simpson, 2001; Thaler \& Shefrin, 1981). Computational models link temporal discounting to reward processing by implementing the temporal difference error, a formal teaching signal in artificial reinforcement learning (Schultz, 1998; Schweighofer, Tanaka, \& Doya, 2007).

These views highlight the separate influences of time and reward on intertemporal choice. However, their interplay has even more facets. For example, a preference reversal can be induced, leading to a voluntary delay, if outcomes are presented as sequences of events, instead of as individual events (e.g., Loewenstein \& Prelec, 1991, 1993). A possible explanation for this is a general preference for improving sequences: People prefer it if things are getting better (Frederick et al., 2002). Such a perspective, in which an intertemporal choice option is only one part of a sequence of rewards, could also explain the usual preference for earlier rewards. If the temporal distance to the chosen reward controls the reward rate, choosing the smaller interval is a way to maximize this rate (Grace, 1999; Myerson \& Green, 1995; Rachlin, 1971). Transience, another time-dependent feature of rewards, also affects intertemporal choices (Loewenstein, 1987). If a reward is fleeting, subjects will voluntarily delay it in order to extend the transient reward via the positive feeling of anticipation. Together, these findings point toward a complex interaction of time perception and reward anticipation in temporal discounting.

How can neuroscience contribute to an understanding of this complex involvement? Temporal discounting is found to be affected severely by lesions of the orbitofrontal cortex (Roesch, Calu, Burke, \& Schoenbaum, 2007). This region, together with the basal ganglia and the striatum, is highly involved in valuation and prediction of future reward (Knutson \& Cooper, 2005; Montague \& Berns, 2002; Montague, King-Casas, \& Cohen, 2006). On the other side, fronto-striatal circuits modulated by dopamine are crucial for temporal processing (Hinton \& Meck, 2004; Nenadic et al., 2003; Wittmann et al., 2007), and serotonin is supposed to control the time scale of reward prediction by regulating neural activity in the striatum (Tanaka et al., 2007). Taken together, neuroscientific research indicates that similar brain regions are involved in time perception, reward anticipation, and intertemporal choice.

However, it remains open whether similar activation patterns for time perception and reward anticipation reflect interactions between these processes and how these interactions might relate to temporal discounting.

Integration efforts. Many further theories and models have been introduced in order to explain and predict intertemporal choice behavior. Several researchers have, for instance, suggested a connection between temporal and probabilistic discounting (for a review, see Cardinal, 2006; Green \& Myerson, 2004), so that people discount immediate but probabilistic rewards and certain but delayed rewards similarly. Although a single-process account of probabilistic and time discounting cannot be sustained (Green \& Myerson, 2004), the subjective probability of obtaining a delayed reward decays hyperbolically and, thus, contributes to temporal discounting (Takahashi, Ikeda, \& Hasegawa, 2007), as is proposed by an evolutionarist mathematical model (Sozou, 1998). Other researchers have claimed that people use simple choice heuristics (e.g., Benhabib, Bisin, \& Schotter, 2004; Glimcher, Kable, \& Louie, 2007), which are somehow biased by reference points (Frederick et al., 2002) or personal preferences (Gul \& Pesendorfer, 2001).

Overall, the amount of empirical findings in this field is overwhelming (Frederick et al., 2002). Despite this and 
the number of disparate theories explaining intertemporal choice, a compelling biological or computational specification is still missing. Therefore, we join the claim of a more recent review (Berns et al., 2007) that a unifying account of intertemporal choice is needed that will incorporate empirical results on self-control (Ainslie, 2005), reward anticipation (Montague et al., 2006), and time representation (Wittmann \& Paulus, 2007).

With the described challenges at hand, what could be the next steps? In the following, we will approach intertemporal choice from the perspective of DST. We will argue that an empirical approach based on DST could contribute to more integration of intertemporal choice and neuroeconomics by offering a common theoretical framework as a mental model and, building on that, an empirical tool set.

\section{A DST-INFORMED APPROACH TO DECISION MAKING}

DST, originally coming from physics and mathematics, has previously been introduced as a useful perspective on human behavior. Several scholars have introduced it into specific subdisciplines - for example, social psychology (see Vallacher, Read, \& Nowak, 2002), emotion psychology (Lewis, 2005), developmental psychology (Granic \& Hollenstein, 2003; Thelen \& Smith, 1996), motor coordination (Kelso, 1995), and philosophy of action (Juarrero, 1999).

We will start with a basic picture of dynamic cognitive systems, including a review of DST-informed work on various aspects of cognition. Following this, the general concepts of DST will be introduced and applied to decision making in order to establish the new mental model for the reader. On the basis of this mental model, we will then offer behavioral and neuroscientific research strategies as a DSTinformed extension to the current empirical tool set.

At this point, it shall not be concealed that the dynamic approach to cognition has also raised an ample theoretical debate about its advantages and disadvantages. For the sake of clarity in the introduction, these issues will be addressed separately in the final discussion (see below).

\section{From Self-Organized Cognition to Continuous Self-Organized Decision Making}

The heart of the DST perspective is that the behavior of systems (and therefore, also cognition as the behavior of the brain) is self-organized and continuous. Selforganization refers to the phenomenon of coherent order emerging spontaneously from the nonlinear interaction of simple system elements. Examples can be found across different disciplines - for example, in physics (e.g., Haken, 2004), biology (e.g., Kauffman, 1993), and medicine (e.g., Bélair, Glass, an der Heiden, \& Milton, 1995). Continuity emphasizes the view that cognition is an everongoing process that does not occur stepwise: The main properties of this process cannot be found in stable and discrete states, but in the transition between these seemingly stable states (Spivey \& Dale, 2004).

Interest in the continuity and self-organizing principles of cognition has been growing steadily during the last decade. This development occurred in parallel with the growing influence of connectionism (McClelland \& $\mathrm{Ru}-$ melhart, 1987), theories of embodied cognition (Clark, 1999; Thelen, Schöner, Scheier, \& Smith, 2001), and evolutionary cognitive robotics (Harvey, Di Paolo, Wood, Quinn, \& Tuci, 2005; Ruppin, 2002).

The continuous and self-organizing nature of dynamic systems builds on a phenomenon described by the concept of circular causality: Whereas the system's single elements drive the whole system in the direction of a new pattern of coherent order, this strengthening pattern enslaves the whole system by acquiring more and more single elements. As a result, a new order emerges seemingly out of nothing and quite suddenly. This way, the interplay of positive feedback loops (the rise of a new pattern) and negative feedback loops (the stabilization of a pattern) creates the nonlinear behavior of a system, without a controlling instance and a clear first cause (Haken, 2004). From the outside, these nonlinear dynamics are observable as (seemingly) sudden shifts in a system's behavior, (seemingly) random behavior, and the strong dependence of a system's behavior on its environment.

The nonlinear, continuous, and self-organizing principles of cognition have been studied by scholars from all the different fields investigating decision making. In economics, principles of self-organization have been applied as an explanation for the complexity of macro- and microeconomics (Arthur, 1999; Rosser, 1999, 2007). In psychology and neuroscience, recent research has included studies of leadership behavior (Guastello \& Bond, 2007), self-esteem (Delignières, Fortes, \& Ninot, 2004), self-control (Warren, Sprott, \& Hawkins, 2002), emotion (Lewis, 2000, 2005), empathy (Guastello, Pincus, \& Gunderson, 2006), motor development and coordination (Athènes, Sallagoïty, Zanone, \& Albaret, 2004; Bardy, Oullier, Bootsma, \& Stoffregen, 2002; Clearfield, Diedrich, Smith, \& Thelen, 2006; Kelso \& Zanone, 2002; Lagarde \& Kelso, 2006), cognitive development (Thelen et al., 2001), social development (Granic \& Patterson, 2006), judgment (van Rooij \& Bongers, 2000), learning (Churchill, 2008; de Bot, Lowie, \& Verspoor, 2007; Kostrubiec, Tallet, \& Zanone, 2006), language and speech (Almonte, Jirsa, Large, \& Tuller, 2005; McDougall, 2006), dynamic adaptation in complex tasks (Kozma, Harter, \& Achunala, 2007), perception (Giraudo \& Pailhous, 1999; Rodriguez et al., 1999), and neural coordination (Freeman, 2003; Kerick, Hatfield, \& Allender, 2007; Varela, Lachaux, Rodriguez, \& Martinerie, 2001). Evidence for a self-organizing basis of cognition has also been provided by a large number of modeling studies simulating empirical data, covering a diverse collection of topics-for example, language (Elman, 2004; Farrar \& Van Orden, 2001; Li, Farkas, \& MacWhinney, 2004; Mitchener \& Nowak, 2004; Rueckl, 2002; Tabor \& Tanenhaus, 1999), initiation of movements (Erlhagen \& Schöner, 2002), action control (Beer, 2003), working memory (Deco \& Rolls, 2003), emotion (Thagard \& Nerb, 2002), and stereotype change (Queller, 2002). Further support has been provided by a rising number of cognitive models successfully implemented in robotics (e.g., Harvey et al., 2005; 
Ruppin, 2002). Taken together, this research has accumulated evidence suggesting that the principles of continuous self-organizing cognition can explain how an agent fulfills complex tasks in a complex environment.

How can we apply these principles to research on decision making? Until now, only a few DST-informed empirical studies about decision making have been conducted. However, the results of these studies show that investigating continuous self-organized decision making is in principle possible. For example, Coulson and Nunn (1999) investigated sequences of decisions and found socalled catastrophe flags - that is, patterns in the data indicating self-organization. And Svyantek, DeShon, and Siler (1991) investigated the framing of decisions over trials, drawing similar conclusions. Richards (1990) has shown evidence for nonlinear interactions emerging in an economic game for two players, and Richards and Hays (1998) have investigated decision behavior in navigation, again providing evidence for underlying nonlinear processes.

Moreover, the modeling of continuous self-organized decision making offers insight into a variety of phenomena, such as inconsistencies among preference measures (Townsend \& Busemeyer, 1995), perceptual decision making (Loh \& Deco, 2005; Loh, Pasupathy, Miller, \& Deco, 2008; Wang, 2002; Wong, Huk, Shadlen, \& Wang, 2007), seemingly random behavior (West \& Lebiere, 2001), loss aversion (Usher \& McClelland, 2004), or even the Coca Cola crisis (Leven \& Levine, 1996).

Taken together, the empirical and model-based findings indicate that decision making can be conceived of as a continuous self-organized cognitive process.

\section{Principles of DST and Their Application to Decision Making}

To study continuous self-organized decision making, one needs a language that can describe the underlying dynamic structure of the system. DST offers a framework of concepts for this purpose (for more comprehensive introductions, see, e.g., F. D. Abraham, 1990; R. Abraham, Gardini, \& Mira, 1997; L. M. Ward, 2001).

In the following, we will introduce these concepts and their neural implementation step by step and will apply each step to a decision model of intertemporal choice. For reasons of comprehensibility, this introduction will stay at an abstract and graphical level and will avoid the complexities of differential equations (see, e.g., Townsend \& Busemeyer, 1989, for an example of modeling a similar system with differential equations).

Systems, variables, and state space. What is a dynamic system? DST formally describes dynamic systems by a set of differential equations, defining the variables necessary to describe the system and the underlying interaction of its elements. Consequently, the behavior of a real system can be represented by the combination of all relevant variables - that is, a specific pattern of values at each moment in time.

The current pattern of variable values defines the current state of a dynamic system; hence, the variables are also called state variables. This current state can be repre- sented by a point in a state space, ${ }^{7}$ which has one dimension for each state variable. Therefore, the state space contains all possible states of a system. Since the state space is continuous, related states - that is, patterns of similar variable values - lie next to each other. This makes the DST-informed approach inherently geometric and offers a measure of relatedness of states and patterns.

For the neural system, the high-dimensional state space would represent all possible patterns of neural activations; there would be one dimension for each neuron (below, we will describe how this high dimensionality can be reduced).

How can we apply this abstract description to the model of a dynamic decision system facing an intertemporal choice? As a first step, we might imagine that such a system has two decisive continuous state variables - namely, the preferred amount of reward and the preferred latency. The current state of the system would be a combination of the current values of these variables.

Attractors, multistability, and trajectories. Up to this point, we have a static system consisting of patterns of variables defining the states of the system. How does DST describe the dynamics of the system - the rise and fall of self-organized orderly patterns?

The system's possible patterns have different tendencies to change from one pattern to the next one. Only a few patterns are entirely stable, revealing the preference of the system's coupled elements for these specific patterns. Similar patterns change into the stable ones, driven by the underlying interactions of the system's elements.

Consequently, the system states representing the different patterns also differ in their tendency to change and, therefore, in their stability. This interplay defines the dynamics of the system, unfolding over time (van Gelder \& Port, 1995).

The system's dynamics - the stability of different states and their tendency to change-can be depicted as a potential landscape with hills and valleys. Completely stable states, which are preferred by the system, are depicted as valleys of the potential landscape. Since these states attract surrounding states, they are called attractors. The depth of a valley defines the stability of the attractor state. The width of the valley defines the range of attracted neighboring states. Extremely unstable states are depicted as the peaks in the potential landscape. Since these states show a strong tendency to change into states lying nearby, they are called repellors (compare Figure 2A).

Although it is possible for a dynamic system to have no stable or only one attractor state (cf. Figure 2A), common dynamic systems have several attractors at the same time; these systems are called multistable (cf. Figure 2B). The attractor state in which the system stabilizes is determined by the size of the attractors' basins; the attractor with the greatest influence drags the system into its basin.

The change of the system's state through time, from one pattern to the next one, is defined as the trajectory of the system, often depicted as a path through the potential landscape (see Figure 3). Due to the continuity of the state space, changes of one state into another are continuous transformations, instead of discrete ones. 

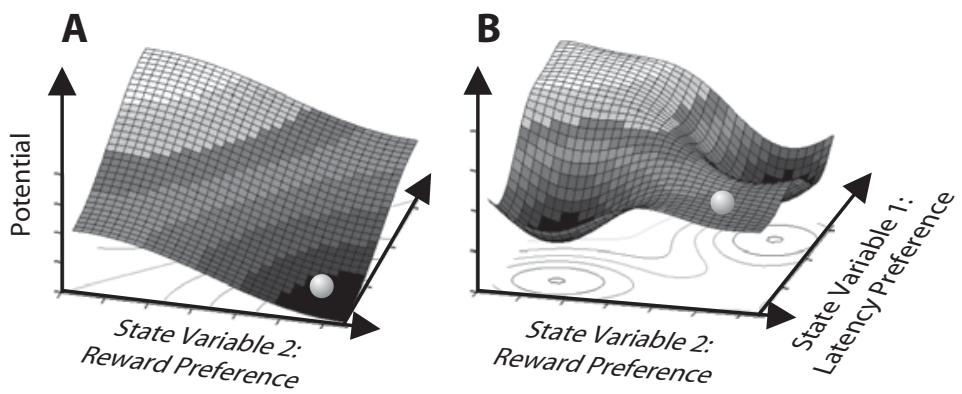

Figure 2. The state space of a dynamic decision system with two state variables, depicted as a potential landscape of hills (repellors) and valleys (attractors). The current state of the system is marked by a ball. (A) The intrinsic dynamics tend to maximize reward at the shortest possible latency. (B) The presentation of two equally valued options modulates the intrinsic dynamics, and two stable attractors emerge.

In the neural system, attractors may be defined by the preferred formation of specific neural assemblies (Varela et al., 2001) or population codes (Spivey, 2007). The trajectory of how the system approaches an attractor would represent the rising stability of a specific assembly formation.

The development of a specific decision can be depicted as the trajectory through the state space of the decision system (see Figure 3). Typically, the system shows preferences for specific patterns of decisions, indicated by its potential landscape. If one attractor in this landscape is broad and deep and the others are flat and narrow, the system most likely will end in the broad, deep, and therefore stable attractor state; a decision will be made easily and consistently. In the case of equally attractive options, the final decision will be dependent on other factors (see below).

How does this system finally perform its choice? If not paced from the outside, a choice could be elicited if the system remains in the attractor for a critical time period long enough to enable the accumulation of sufficient neural activation to cross the reaction threshold (see, e.g., Townsend \& Busemeyer, 1995; Wilimzig \& Schöner, 2005).

Collective variables. Points in the state space mark the current values of all the state variables of the system. These variables map the phenomena of interest (analogue to the classical dependent variables). The state variables do not necessarily map a single system property or measurement but can result from a combination of measurements. Due to this combinatorial nature, the state variables of a dynamic system are called collective variables. ${ }^{8}$

Because of the high complexity of cognitive systems, Kelso (2000) emphasized the importance of describing the system of interest with as few state variables as possible. As the name indicates, collective variables are constructs capturing the properties of interacting components of a system. Therefore, a collective variable at the level of the abstraction of interest could be described as several collective variables at a lower level of abstraction. To put it differently, modeling the behavior of a system at a specific level of abstraction requires that the definition of the dimensions of the state space be as compact as possible, in order to reduce complexity without losing predictability. ${ }^{9}$
For the neural system, we can use collective variables to reduce the dimensionality of the state space. Introducing a first level of abstraction, we can use the coordinated activity of groups of neurons as collective variables (Bressler \& Kelso, 2001).

For our model of a decision system in intertemporal choice, we could combine the two state variables reward preference and latency preference into one collective variable of interest, called option-preference (see Figure 4).

Control parameters, bifurcations, and phase transitions. At this point, we have the tools to describe the dynamics of systems existing independently of environmental changes (see Figure 2).

Since cognition is dependent on its continuous interaction with a changing environment, it is described better as a coupled system. To describe this coupling, DST uses control parameters (analogous to independent variables).

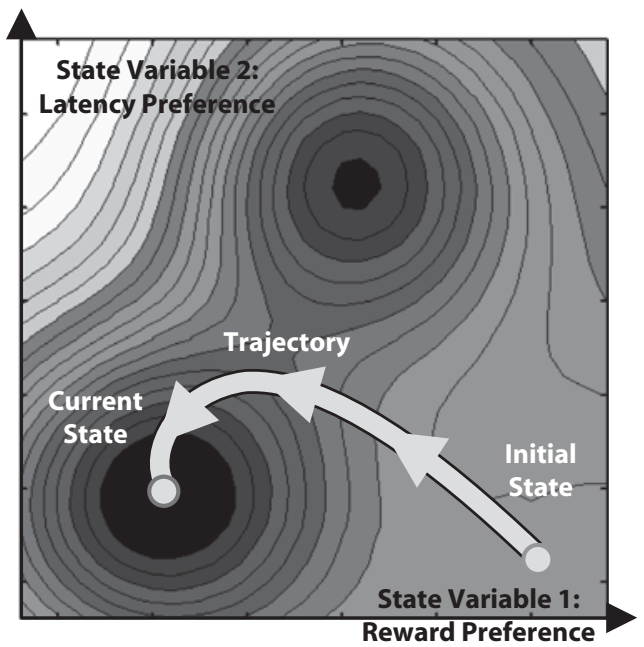

Figure 3. The state space of a dynamic decision system with two unequally valued options. The trajectory defines the history of states: Starting from the originally stable state of maximum reward and shortest latency (cf. Figure 2A), the change of the potential landscape by the option presentation moves the system state to one of the options from which to choose. 


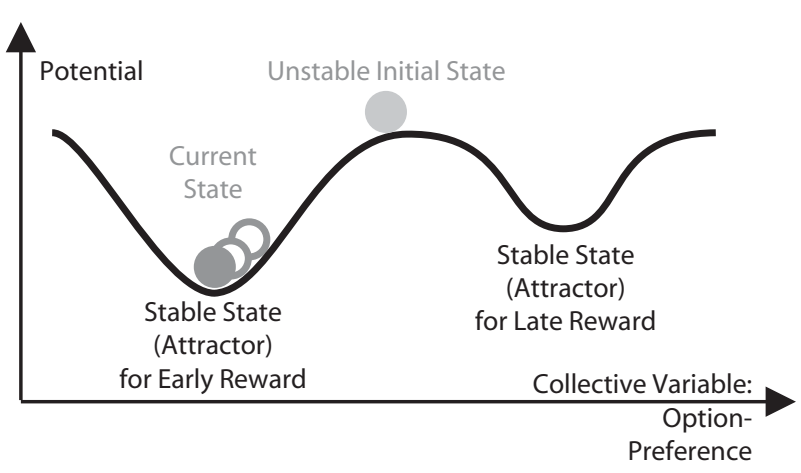

Figure 4. The state space of the dynamic decision system reduced to one collective variable and two stable states for two unequally valued options. In this case, the early option is more attractive.

These parameters do not directly affect a system's state but modify the architecture of the system's landscapefor example, by creating new attractors or destroying old ones. Due to this indirect influence, the effect of a control parameter is nonlinear (see Figure 5). Gradually changing it can have no observable effect on the system's dynamics for a large range of parameter values. Only when a certain value of the control parameter is reached might new attractors emerge or existing attractors vanish suddenly. At these moments, the system's state can change abruptly, leading to sudden differences in behavior. These sudden changes are called phase transitions or catastrophes (see, e.g., Stewart \& Peregoy, 1983).

In the neural system, stable assemblies can be weakened by a control parameter - for example, the increasing speed of a cyclic hand movement in a motor coordination task (see Kelso, 1995). At a certain point, the assembly breaks up and another assembly takes over. The same holds for neurons in a working memory task. Using item similarity as a control parameter, two items can be coded by two separate assemblies (Johnson, Spencer, \& Schöner, 2006). If the items become too similar, the sepa- rate assemblies merge into a new assembly coding both items together.

For the decision system in an intertemporal choice task, we can use two properties of the choice alternatives as control parameters: difference in reward value and time delay (for simplicity, we will stay with these two exemplary parameters, although, of course, many more are thinkable).

The influence of these control parameters can be observed in a bifurcation diagram (see Figure 5): Because of the interaction with the intrinsic dynamics (see Figure $2 \mathrm{~A}$ ), an option promising a reward soon will produce a broad and deep attractor, whereas an option promising the same reward, but delayed, will produce no attractor at all. Raising the reward for the second option first shows no effect, until at a certain point, a new attractor emerges; the second option can now also be chosen.

Hysteresis. With regard to catastrophes, dynamic systems show a striking property called hysteresis (see, e.g., Kelso et al., 1995): a phase transition in the state of a dynamic system can occur at different values of the control parameter, depending on the direction of parameter change. Hence, the same input can cause different outputs of the system, depending on the system's history (see Figure 6).

In the neural system, assemblies of interconnected neurons have an intrinsic stability due to lateral inhibition (see Raffone \& Wolters, 2001). Thus, for new assemblies to take over, the coherence of the current assembly has to become extremely weak. In the above-mentioned working memory model (Johnson et al., 2006), the two similar items grouped together in one assembly have to become very dissimilar again to break up the grouping.

In our model of a decision system, effects of hysteresis also become visible if several subsequent decisions have to be made. The initial state of the decision system in a trial is now influenced by two factors: the system's intrinsic dynamics and its final state in the previous trial (cf. Figures $2 \mathrm{~A}$ and 3 ). Although the attractor layout changes from trial to trial, due to the changes in the control parameters (e.g., reward difference; see Figure 6), the system's state is caught in one of the attractors: The system persists in

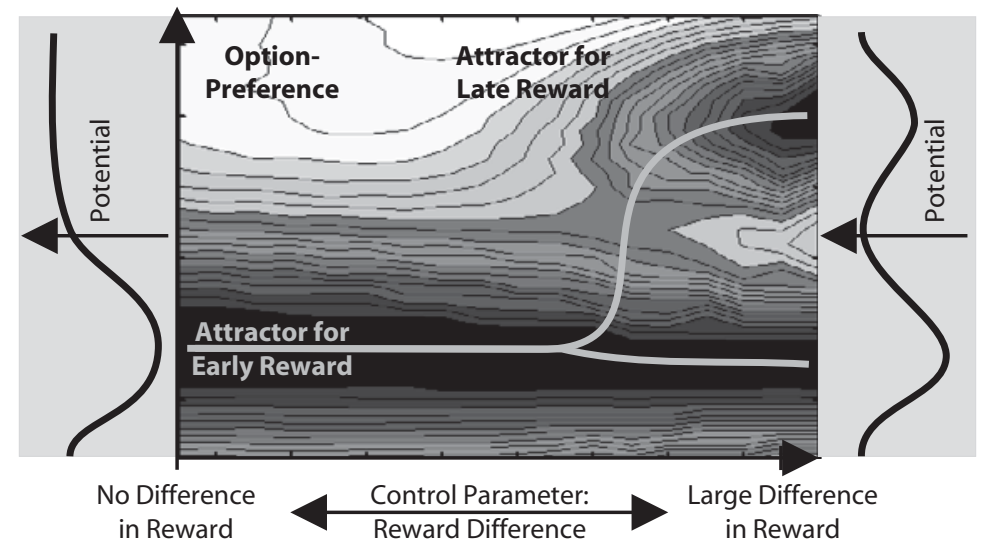

Figure 5. A bifurcation diagram showing the changes of the system's attractor layout as a function of a control parameter - that is, a difference in reward between two options. Abrupt changes in the attractor layout due to nonlinear interactions lead to sudden changes in the system's behavior. 


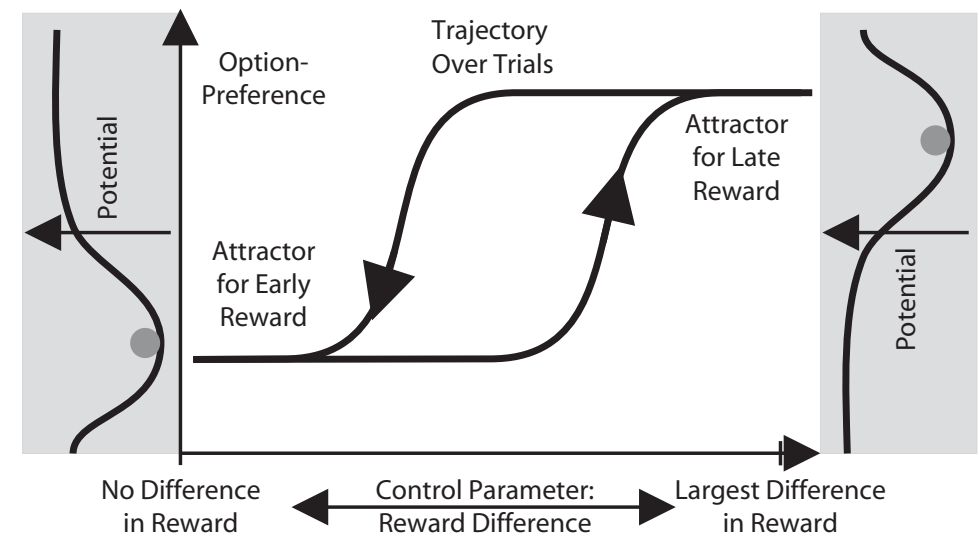

Figure 6. Hysteresis or catastrophes are a typical feature of phase transitions in a dynamic decision system: the dependence on the direction of change. A socalled cusp catastrophe is depicted.

its choice behavior. Only when the originally dominant attractor vanishes, due to the control parameter change (see Figure 5), does a phase transition occur, and the system's state is dragged into the new attractor. Therefore, transitions in the system's choice behavior (e.g., from shortterm to long-term decisions and vice versa) can occur at different values of the control parameter, depending on the direction of the parameter change.

Perturbations and criticality. In principle, the state of a dynamic system is governed by its attractor layout, which, in turn, is influenced by control parameters. Sudden direct influences on the system state, which do not affect the attractor layout but, rather, change the collective variable directly, are called perturbations. These disturbances can cause the system state to change and even to leave the current attractor basin. If the system is settled in a stable attractor, it takes a lot of energy to perturb the system's behavior effectively (see Figure 7).

The interaction of the influences of control parameters and of perturbations becomes evident when the system reaches so-called criticality: The changing control parameter has altered the attractor layout of the system, several attractors have almost vanished, and a phase transition is imminent. In this situation, perturbations can cause one of two phenomena: Either it takes less energy to move the system out of the weakened attractor state into the basin of another attractor; or, if the system still stays in its weakened attractor state, it takes more time to restabilize.

Watching the dynamic system from the outside, a control parameter might not appear to affect the collective variable for a long time - if one looks only at the mean value of the measurement. However, the effect of control parameter alterations might be visible in the increased variability of the measured variable, with a flatter attractor leading to higher variability. Therefore, in contrast to classical approaches, DST-informed research regards variability in the measured data as the signal, not the noise (Thelen, Ulrich, \& Wolff, 1991).

In the neural system, an assembly of neurons could be perturbed by a new burst of input. If the neural system is stable - the assembly's coherence is still strong - the perturbation might cause only small fluctuations. If the neural system is critical-the assembly's coherence is weak (but still present, due to its intrinsic stability) - the perturbation could break up the assembly.

What do perturbation and criticality mean for the decision system? Criticality comes into play when decisions are difficult to reach and the attractors for the decisions become very flat (and therefore unstable). The system is susceptible to even small perturbations from the environment, leading to seemingly stochastic decisions (see Figure 8).

Moreover, using directed perturbations, a critical system can be swayed quite easily, trimming its sails to the wind. In an intertemporal choice paradigm, making the early and the late choices undesirable could lead to this critical state of the system: Even small influences from the outside could cause long hesitation (slow restabilization) or change the decision (by switching to another attractor basin).

Metastability and intermittency. So far, we have conceived of the attractor landscape of a dynamical system as possessing stable attractors and exhibiting a strong intrinsic stability as long as there is no change in control parameters. As several scientists have emphasized, this limited model does not suffice to account for the fact that natural cognitive systems are characterized by both flex-

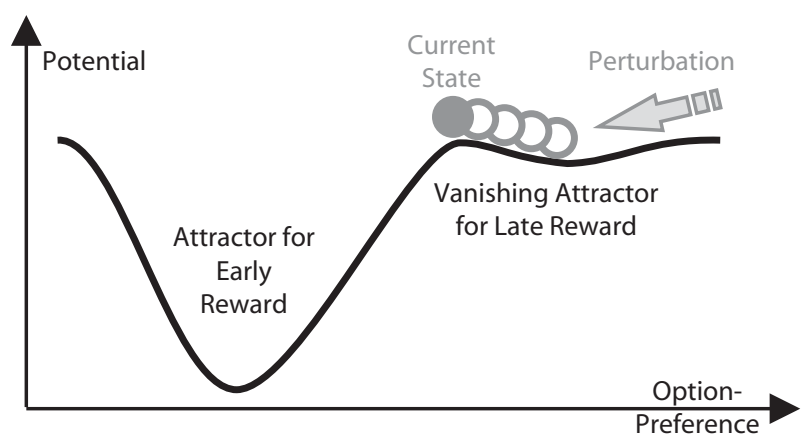

Figure 7. A perturbation of a critical decision system can cause a permanent change in the system state. 


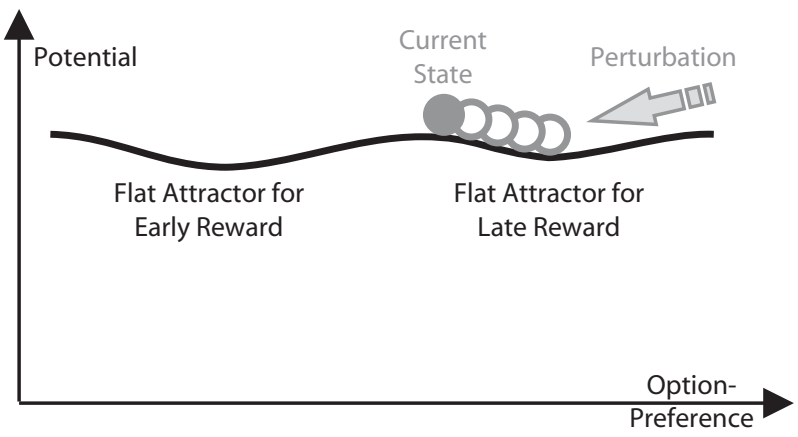

Figure 8. Small perturbations can easily influence a highly undetermined decision.

ibility and stability (Bressler \& Kelso, 2001; Kelso, 1995). To incorporate this additional aspect, the simple multistable model must be extended by two properties, leading to the concept of metastability. Now the system does not contain stable attractors anymore. Instead, it consists of flattened "phantom" attractors: remaining areas of metastability. Metaphorically speaking, the deep valleys of stable attractors are replaced by planes (see Figure 9). Consequently, the system state constantly shifts between these metastable "phantom" attractors: It oscillates between two options.

Now the system implements stability and flexibility at the same time. A system's state changes very slowly while residing in one of the metastable attractor basins; seemingly, it is stable. After leaving the basin, the system moves quite quickly to the next metastable attractor; it is highly flexible. This causes the system to switch between several seemingly stable states, a condition of permanent instability in state called intermittency (Kelso et al., 1995).

In the neural system, metastability emerges due to the loose coupling of neural populations possessing different properties (Bressler \& Kelso, 2001; Varela et al., 2001). Therefore, the neural system stays in a constant flow, changing continuously from one metastable state to the next one (Spivey, 2007).

Similarly, metastability is also an indispensable property of decision systems dealing with the real world. For instance, people have to switch permanently between short-term goals (e.g., appetite now) and long-term goals (e.g., saving money for aliment next week). As this example also illustrates, it would even be dangerous to stick to one of the two strategies (leading to starvation either now or later). Conceptualizing the two alternatives (short-term vs. long-term thinking) as "phantom" attractors, the system state could change constantly. Although internally this change would be continuous, for an observer from the outside, the system would switch between the two potential behavioral patterns (as has been emphasized, e.g., by Townsend \& Busemeyer, 1995).

\section{Research Strategies for a DST-Informed Approach to Intertemporal Choice}

Looking at the amount of DST-informed work, one might ask: Why do modeling studies still, by and large, outnumber empirical studies (see Rosser, 1999)? One possible reason is that DST-informed work demands a radical shift in perspective. Moreover, the mathematical level of description in the field of DST can, at first glance, easily discourage empirical researchers (see van Geert \& Steenbeek, 2005). To inspire and encourage scientists in the field of human decision making, we will present DST-informed behavioral and neuroscientific research strategies adapted to the example of intertemporal choice (for more general overviews, see Granic \& Hollenstein, 2003; Kelso, 1995).

Variability in the dynamic decision system. As was mentioned above, shifting the focus of analysis away from measures of central tendency and toward variability measures plays an important role in a DST-informed approach. The analysis of variability can indicate the dynamic structure of the system in two ways: directly, by analyzing the amount of variability, and indirectly, by analyzing the structure of variability.

The amount of variability. The amount of variability characterizes the stability of attractors of the underlying system: More variance indicates less stability. Behaviorally, one could measure reaction times and analyze their distributions over multiple decisions - for instance, in binary choice tasks (see Diederich \& Busemeyer, 1999). To give another example, one could ask subjects to indicate the amount of money they are willing to pay for an option and then analyze the distribution of these values (see Townsend \& Busemeyer, 1995). The detection of high reaction times and high variability would suggest that the system is not stable and the attractors are flat. Conversely, low reaction times and low variability would indicate the presence of deep and stable attractors.

Neuroscientifically, the investigation of the variability in EEG measures can potentially provide a link between neural and behavioral data by analyzing single-trial neural synchronization (Lachaux et al., 2000), single-trial event related potentials (ERPs; e.g., Delorme, Makeig, FabreThorpe, \& Sejnowski, 2002; Makeig, Delorme, et al., 2004), and intertrial coherence of ERPs (e.g., Delorme \& Makeig, 2004).

The structure of variability. The analysis of the structure of variability potentially allows for inferring specific properties of the underlying system. A prominent example

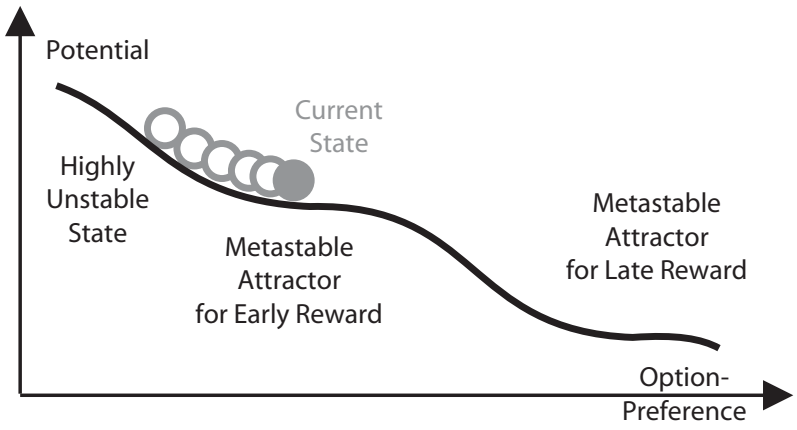

Figure 9. In a metastable decision system, only flattened "phantom" attractors are left; the system is in a condition of constantly shifting stability. Projecting the continuous collective variable onto a cylinder connects the two ends of the dimension circularly; the system can oscillate continuously between different attractor states (Kelso, 1995). 
is that the analysis of spectral properties often reveals a specific temporal structure, called $1 / f$ noise (a $1 / f$ scaled frequency spectrum), a specific property of self-organized systems (see, e.g., L. M. Ward, 2001). The detailed composition of this noise has been shown to depend on task specifics - for example, the decision load (Gilden, 1997). Such results point to a functional role of the noise in the system's dynamics (e.g., Kelly, Heathcote, Heath, \& Longstaff, 2001; Pressing \& Jolley-Rogers, 1997). Interestingly, the $1 / f$ spectrum is found not only in behavioral data, but also in neural data, such as ERPs and ERP residuals (L. M. Ward, 2001). Since noise is usually simply discarded in most studies, it would be a first step to include its spectrum in the analysis (L. M. Ward, 2001) and to investigate its response to experimental manipulations.

Watching continuous changes over time: Trajectories. Since the DST-informed approach focuses on the dynamics of change, the relevant properties can be revealed only by investigating the process of interest continuously (see Magnuson, 2005). Therefore, the focus of empirical research of decision making moves away from the outcome of the decision to the trajectory of the system state within a trial.

How can such an investigation of continuous system properties be performed on the level of behavioral data? As a first approximation, changes over time can be observed by varying the point at which the decision is made - for example, by forcing the choice at a particular moment in a deadline experiment. Variations in the preferred option as a function of choice time would indicate instability; independence of the decision from the time point would indicate stable attractors. The next step would be to use continuous measures, instead of single discrete ones. For instance, the trajectories of the decision process could be tracked by observing the subject's movement toward the preferred choice option-for example, if a computer mouse is used as a response device (see Spivey \& Dale, 2006) or by measuring EMG or eye movements.

Neuroscientifically, such measures as EEG and MEG provide a sufficiently high temporal resolution to investigate the continuous dynamics of neural activity. One approach could be to inspect fluctuations in neural coherence and synchrony (e.g., Breakspear, Williams, \& Stam, 2004; Delorme et al., 2002; Lachaux, Rodriguez, Martinerie, \& Varela, 1999; Weiss \& Mueller, 2003) and oscillatory behavior (e.g., Basar, Basar-Eroglu, Karakas, \& Schürmann, 2001). Differences in the timing of synchronization could indicate different amounts of instability. Another approach could be to investigate how the attention covered shifts between different decision options over time by using steady state visual evoked potentials (tagging of stimuli with flicker frequencies; see, e.g., Müller, Andersen, \& Keil, 2008; Müller, Teder-Sälejärvi, \& Hillyard, 1998). Differences in signal amplitude could indicate different amounts of attention. This, in turn, might indicate how strongly the choice of a given decision option is being considered. Yet another option is to use single-trial EEG/ MEG analysis (e.g., Makeig, Debener, Onton, \& Delorme, 2004; Philiastides \& Sajda, 2006). For example, such an analysis has been used to examine decision timing in rela- tion to varying degrees of decision difficulty (Philiastides, Ratcliff, \& Sajda, 2006). Finally, it is possible to analyze the coupling of single-trial ERPs and BOLD signals (e.g., Debener et al., 2005). This method could be used as a bridge between the analysis of decision timing and the analysis of related spatial brain structures.

The combined analysis of continuously acquired behavioral data and neuroscientific data (synchronization, SSVEP, single-trial ERPs) could be used to validate results from computational models (Philiastides et al., 2006) - for example, decision field theory models (Busemeyer, Jessup, Johnson, \& Townsend, 2006; Townsend \& Busemeyer, 1995).

Nonlinear influences of control parameters: Hysteresis. By watching changes over time, one can investigate the nonlinear influence of control parameter alterations on the attractor layout of the decision system. In temporal discounting, reward value and the time delay of decision options are promising control parameters. To observe the specific points of phase transitions between different attractors and to detect criticality, we need to change the control parameters continually, rather than in a random fashion. For example (see Figure 10), one could vary the time delay of the first reward (sooner but smaller) from zero to the fixed delay of the second reward (later but larger).

The amount of the reward remains constant: The first reward should be large enough to be chosen reliably if it is offered immediately, and it should be low enough to be disregarded if offered simultaneously with the second reward. Hence, at both extremes of this manipulation, the state space of the system will have only one of two possible attractors: one for the first reward if the delay is zero, and one for the second reward if the delays are equal (since the amount of the second reward is larger).

The time delay at which the decision switches from the first to the second reward marks the phase transition. If this time delay varies as a function of the direction of changes in the time delay, hysteresis can be observed behaviorally. Hysteresis can also be determined neuroscientifically when the same stimulus evokes different brain activations, depending on the direction of change (e.g., ERPs in Kelso et al., 1995). We expect that similar results might be observable in the exemplary decision task. More speculative, but supported by recent findings regarding differential neural correlates of consciousness (see Melloni et al., 2007), it might be possible to find neural patterns representing both the nonlinear and the continuous sides of the decision system: hysteresis for one kind of measure (e.g., ERPs or long-range synchrony) and continuous change for other measures (e.g., neural oscillations).

Using perturbations to detect properties of the system. To get further information about the dynamic structure of the decision system, one can systematically induce variability into the system. According to Kelso (1995), the interesting properties of a system can be found by driving it near criticality, when the system's attractors become less and less stable. At these moments, a dynamic system is very sensitive to even small perturbations (see above).

In an intertemporal choice task, perturbations could be implemented as a slight impulse in the direction of one choice option during the initial phase of a selecting mouse 


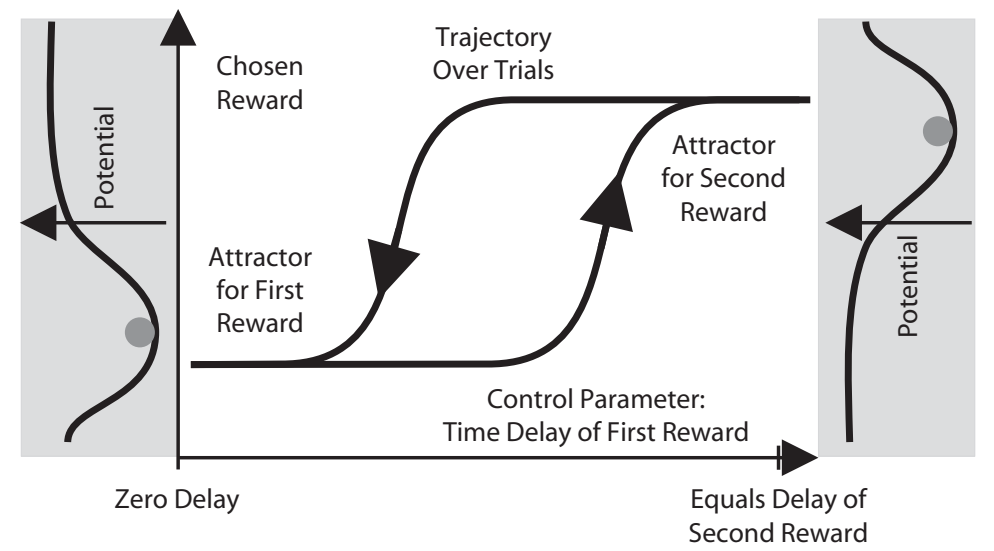

Figure 10. The setup of a dynamic-systems-theory-informed experiment investigating nonlinear influences of control parameter (the time delay of the first reward) changes on temporal discounting; depending on the directions of parameter change, the final decision (chosen reward) will be different for the same time delay.

movement (see Spivey \& Dale, 2006). This should have different influences on the choice finally made, depending on the level of ambiguity of the decision. The deciding brain could also be perturbed directly, by using transcranial magnetic stimulation (TMS). Adopting an approach similar to that which Meyer-Lindenberg, Ziemann, Hajak, Cohen, and Berman (2002) used in a motor coordination study, the impulses of a TMS device could be used to test the stability of decision attractors (see also Gold \& Shadlen, 2007, for testing the stability of a decision in monkeys by electrical perturbation).

The impact of perturbations can be measured behaviorally by use of two indicators: a central tendency, which detects sudden transitions from one system state to another one, and variance, which detects increasing variability indicating a changed (flattened) attractor layout. In the domain of neuroscientific measures, decreases in neural synchrony could indicate the weakening of neural assemblies, whereas changes in the topography of synchrony could indicate the alternation of assemblies (see Rodriguez et al., 1999; Varela et al., 2001).

What additional information can be gained by perturbing the decision system? The advantages of the procedure are twofold. First, it allows for detecting and precisely mapping attractor layouts onto ranges of the control parameter. Second, by analyzing observable nonlinear behavior, it enables the investigation of the hidden continuous influence of control parameters that are difficult or even impossible to observe otherwise (e.g., Kanai, Moradi, Shimojo, \& Verstraten, 2005, for perceptual switching due to fatigue).

Considering individuality to complement aggregation. Another important characteristic of the DSTinformed approach is the investigation and appreciation of single-subject data. This holds in general-for example, for learning paradigms (Heath, 2000; Kelso, 1995; Thelen, 1995) — but also specifically for decision-making research (e.g., Diederich \& Busemeyer, 1999). For the latter, Coulson and Nunn (1999) found that discrete (catastrophic) steps in judgment formation can be identified in singlesubject data, as would be expected for a system exhibiting nonlinear properties (a stepwise change in measures of central tendency; see above). Averaging these singlesubject data, as has been done in practically all current studies, produced a linear relationship between parameter and judgment. It obliterated dynamic phenomena that could have revealed the functional structure of the individual judgment systems. Heath showed for time series data that such negative effects of aggregation can be avoided by using a two-step strategy. First, one needs to carefully extract individual parameters from each subject's time series. Second, the parameters can be averaged over subjects. Such a strategy enables a quantitative analysis without ignoring nonlinear phenomena on the individual level.

In practice, this strategy can be implemented easily during data analysis - before the aggregation of subject data. This way, it might be possible to discover general nonlinear phenomena in decision processes, as has been shown by Coulson and Nunn (1999). For neuroscientific data (EEG/ MEG and fMRI), independent component analysis (ICA) could be used to extract single components from each subject (e.g., Calhoun, Adali, Pearlson, \& Pekar, 2001; Jung et al., 2001; but see Friston, 1998). The conservation of subject-specific properties in the process of aggregating the data over subjects could be accomplished by clustering ICA components according to extracted functional criteria (e.g., spectral perturbations, synchronization, stimulus locking; Makeig, Delorme, et al., 2004; Onton, Delorme, \& Makeig, 2005).

\section{ASSEMBLING THE DST-INFORMED APPROACH}

What are the consequences of embracing the presented DST-informed approach? In the following, we will outline the theoretical impact of applying the enriched mental model and the empirical tool set to intertemporal choice and decision making. 


\section{A DST-Informed Approach to Intertemporal Choice}

In our review about intertemporal choice, we raised three issues central to the scientific discussion about intertemporal choice. We now want to address these issues from the perspective of the developed DST-informed approach.

First, we pointed out some of the difficulties that arise in trying to explain the seemingly "irrational" inconsistencies in temporal discounting. We discussed the behavioral and neuroscientific implications of the dominant two-system approach. The main contribution of a DST-informed approach to these issues could be to show that inconsistent behavior can also result from a single system. The conception of a nonlinear, continuous, and self-organized decision system shifts the interpretation of inconsistencies from being an exception to being one possible manifestation of the rule. There is no need to find separate brain systems that correlate with impulsive choices. Instead, we need to extract the control parameters under which such inconsistent behavior occurs, using perturbations and looking for effects of hysteresis. Thus, seemingly inconsistent behavior can be explained, for example, by differences in the history of the particular trial. Such a conclusion would be further strengthened by results demonstrating a relationship between the direction of control parameter change and the topography of synchronized neural activity. To address the differences in temporal discounting between different populations, we need to direct our attention to individual attractor layouts and to the intrinsic dynamics of the system. This enables us to decide whether behavioral differences are due to a qualitative change in the attractor layout (e.g., different patterns of neural synchronization) or to less stability in the system (e.g., higher variability in neural signals).

Second, we have pointed out disagreements between theories trying to link temporal discounting to time perception and reward anticipation. Instead of distinguishing between a central decision process and separable, unidirectionally operating side factors, a DST-informed approach could integrate multidimensional influences by introducing them as control parameters. This way, the confounding of time and reward in the intertemporal choice task could be avoided. To identify phase transitions and criticality on both the behavioral and the neural levels, nonlinear effects of the control parameters on discounting behavior can be explored systematically with the proposed empirical tool set. With these data at hand, a dynamic model could be built, integrating the different parameters into a timecontinuous holistic decision process.

Third, we agreed with the claim for an integrated theory of temporal discounting. The DST-informed perspective integrates context factors in behavioral models by treating them as essential parts. We chose the two possible control parameters mentioned above only exemplarily for simplicity of explanation. Influences of additional factors on the behavioral or the neural level should be integrated in the model as equal control parameters. Consequently, the mapping of attractor layouts describing intertemporal choice behavior can be systematically refined. This would contribute to the construction of a more plausible and parsimonious model of intertemporal choice based on differential equations or a time-continuous network. Data generated by this dynamic model, in turn, could be the basis for model-based analysis of neuroscientific data (e.g., O’Doherty, Hampton, \& Kim, 2007, for modelbased fMRI analysis), identifying the neural processes of dynamic decision making.

Taken together, the DST-informed approach has to provide evidence for its validity on two levels, empirically and conceptually. On the empirical level, catastrophe flags (e.g., hysteresis; Gilmore, 1981) have to be identified, and control parameters explaining systematic variability have to be extracted. On the conceptual level, a DST-informed model of intertemporal choice integrating diverse findings has to stay consistent in its functional structure. For example, extending the reward dimension of the model into the negative space could add the option of temporal delayed loss. The observed difference in the discounting rates for losses (Murphy et al., 2001) should be reflected in the state space without changing the intrinsic dynamics for reward-related choices and without defining exceptions. Upon fulfilling these criteria, the proposed DST-informed approach could be validated beyond the expected gain in explanatory power.

\section{A DST-Informed Neuroeconomics}

In our introduction to neuroeconomics, we identified two challenges of current integrative efforts in neuroeconomics: first, divergent levels of description in interdisciplinary collaboration, resulting in the use of metaphorical explanations, and second, a focus on the spatial structure of decision systems. In the following, we will show how the DST-informed approach addresses these issues - first, by providing a common language, and second, by contributing different principles for investigating the deciding brain.

A common language, offering new tools. Within the current framework in neuroeconomics, there is a discrepancy between the terms and concepts of the different disciplines (see above). To avoid "correlating apples and oranges" (Kelso, 1995, p. 29), it is necessary to unify the descriptions of physical and mental activities when relating models from different levels of description (see Kelso, 1995; Spivey, 2007; L. M. Ward, 2001).

The language of DST could provide this unified framework, due to three of its properties. First, since DST provides a common language for the description of phenomena at different levels, it enables the transfer of knowledge between levels of abstraction: A collective variable at one level reflects the interplay of coordinated components at a lower one (Kelso, 1995; but see the discussion on possible complexities with collective variables and metaphorical descriptions).

Second, DST relates different time scales; it provides tools to describe changes on very short (e.g., within an experimental trial) and very long (e.g., longitudinal studies) time scales (van Gelder \& Port, 1995; but see Summers, 1998, for issues at the developmental scale). Although perturbations can identify changes on very short time scales, alternations of attractor landscapes can occur 
over longer time scales - for example, by changes in control parameters.

Third, DST can be used for describing physical and mental behavior (see Spivey, 2007). The nervous system can be perceived as a system tightly coupled to its environment: There is no strict "inside" and "outside" (e.g., Beer, 2000; Maturana \& Varela, 1987). This holds even for very simple organisms, such as the well-known Aplysia (Proekt, Brezina, \& Weiss, 2004) or bacteria (Jonker, Snoep, Treur, Westerhoff, \& Wijngaards, 2002). From such a perspective, the deciding brain uses the environment as a constraining and supporting factor (Clark, 1999; see the Discussion section for issues of antirepresentationalism). To describe and investigate such an embedded system, DST can provide the language for crossing the borders between mental and physical processes (Kelso, 1995; but see, e.g., Van Leeuwen, 2005, for the problem of complexity).

Dynamic structure, nonlinearity, continuity, and self-organization: New principles for the deciding brain. Studies in neuroeconomics often apply a locationoriented, linear, and stepwise approach to the human decision-making processes (see, e.g., Braeutigam, 2005). The brain, however, is a highly integrated organ characterized by recurrence, nonlinear effects, and time continuity (see Engel, Fries, \& Singer, 2001; Spivey, 2007).

Considering these dynamic properties has implications on the neuroscientific and the behavioral levels.

On the neuroscientific level, many current studies focus on linking spatial structures of the brain to processing stages (e.g., Camerer et al., 2005). This should be complemented by the investigation of the system's dynamic structure (see Stephan, 2004; L. M. Ward, 2001). ${ }^{10}$ The feasibility of such an approach is supported by DSTinformed studies (see, e.g., Meyer-Lindenberg et al., 2002; van Orden, Holden, \& Turvey, 2003) and also by recent modeling studies. For example, R. Ward and Ward (2006) were able to show that hierarchically structured, localistic conflict-monitoring architectures (e.g., Botvinick, Braver, Barch, Carter, \& Cohen, 2001) could be replaced by flat, time-continuous network architectures. Similarly, models based on dynamic field theory (e.g., Johnson et al., 2006; Schöner \& Thelen, 2006) focus on the dynamic properties of the neural system and group neurons according to their functional role, irrespective of their spatial location. This way, such models implement dynamic structures in a biologically plausible way (e.g., Erlhagen \& Schöner, 2002).

Such an extended approach supports the transition from spatial structural views postulating multiple decision systems (e.g., Camerer et al., 2005) to "a more synthetic view" (Glimcher et al., 2005, p. 253) of a single decision system being driven at the two extremes of a continuous dimension (e.g., Sugrue et al., 2005). This shift is also supported by dynamic modeling studies, which provide evidence for divergent behavior in holistic systems caused by multistability and bifurcations in the state space (e.g., Jaeger \& Christaller, 1998). In the end, using data from dynamic models in fMRI analysis (see O'Doherty et al., 2007) could help to link the spatial and the dynamical aspects of decision making.
On the behavioral level, the application of the dynamic principles is a necessary enhancement as well (Kelso, 1995; Spivey \& Dale, 2006; van Gelder \& Port, 1995). This has been illustrated, for example, by Townsend and Busemeyer (1995), showing that several paradoxical phenomena in human decision making can be explained by simply including recurrence and time in their model of the decision processes. Moreover, West and Lebiere (2001) have shown that seemingly random human decision behavior can be explained by including nonlinear coupling in decision models. The two examples indicate that it is worthwhile to integrate these principles into current research practice.

Putting the pieces together, we can approach the final question: Who makes the decision in the brain? It is difficult to answer this question without proposing one cognitive component after the other (Kelso, 1995) or, to put it metaphorically, a "loan on intelligence" (Dennett, 1971, p. 96), which results in an infinite regress. A DSTinformed approach to decision making tries to answer the question by identifying processes of self-organization (Beer, 2000; van Orden et al., 2003). The decision behavior is driven by the system's dynamic structure and emerges from the nonlinear time-continuous interaction of the system's elements (see Juarrero, 1999; Kelso, 1995; Tschacher, Dauwalder, \& Haken, 2003); the static central decider has vanished.

\section{DISCUSSION}

We have presented the contributions of a DST-informed approach to the investigation of intertemporal choice and decision making in general. Offering new perspectives on unresolved questions, our aim has been to provide an inspiration for further empirical research.

However, there might be objections that could prevent scientists from trying to integrate the proposed approach into their work. In the following, we will discuss two classes of possible objections: theoretical and practical objections.

\section{Theoretical Objections}

During the past decades, the dynamic approach to cognition has been discussed extensively in the cognitive sciences, especially in philosophy under the term $d y$ namicism. This general debate has identified a number of important objections (for an overview, see Eliasmith, 1996), which we will discuss in order to substantiate the moderate empirical DST-informed approach to decision making proposed here.

A first point of criticism is that the dynamic approach is not really a new paradigm for the cognitive sciences providing a complete account of cognition. Most of the dynamic concepts were introduced by the connectionist paradigm (see Eliasmith, 1996).

We partly agree with this argument: The DST-informed approach is not a new paradigm, but a complement to connectionism. In fact, most of the models we have introduced so far are connectionist and propose dynamic principles. The crucial addition is the shift from a discrete, 
component-oriented, and structural view to a continuous, interaction-oriented, and functional view on cognition (Beer, 2003; Thelen \& Bates, 2003; van Orden et al., 2003). From our perspective, the question is not whether the brain is a network or a dynamic system. Rather, the question is whether it is sufficient to focus on the modular component structure of a network, dividing it into mostly separate systems for stepwise processing, or whether this view should be extended by including the analysis of the continuous, nonlinear, functional properties of the system (sometimes by even ignoring its spatial structure).

Regarding empirical work, we emphasize that by means of the mental model and the empirical tool set of our DST-informed approach, we could deal better with the complexity inherent in cognitive systems, instead of artificially simplifying them (see Beer, 2000; Goldberg \& Markoczy, 2000; Spivey, 2007). Therefore, the approach represents a valuable extension to an empirical scientist's tool set for the investigation of cognitive processes.

A further highly controversial issue pertains to the denial of representations, emphasized by several proponents of the dynamic approach to cognition (e.g., van Gelder, 1998). Several authors consider antirepresentationalism central to the dynamic approach (see Eliasmith, 1996).

In our view, antirepresentationalism is not essential to the dynamic approach to cognition (and not essential to a dynamic approach to decision making either). Rather, we defend the less radical view (also found in, for instance, Clark \& Toribio, 1994; Keijzer \& Bem, 1996) that a dynamic model of cognition does allow for dynamic representations. Nevertheless, a DST-informed approach does require adopting a different view on the nature of representations, so that they are neither static nor localized (Clark, 1997). Instead, they should be understood as patterns of activation that are continuous both in time and in space (Spivey \& Dale, 2004).

Concerning the explanatory power of the approach, it has been argued that the dynamic approach has not yet provided a substantive model of how lower level processes can actually lead to adaptive cognition and behavior (see Keijzer \& Bem, 1996). Following the ecologist approach, it even postulates the irrelevance of biological substrates (Summers, 1998).

We agree that every approach, and especially the dynamic one, must show links across different levels of complexity. We also agree with the criticism of the extreme dynamicist position, which denies the need to account for biological substrates. Therefore, this article has presented evidence for the conceptual and the biological plausibility of a DST-informed empirical approach.

Regarding the conceptual plausibility of a DST-informed approach, we have reviewed several models demonstrating how typical (even paradoxical) human behavior can emerge from the nonlinear interactions of low-level elements and low-level principles of neural function (e.g., Erlhagen \& Schöner, 2002; R. Ward \& Ward, 2006). We have also reviewed studies that have demonstrated how signs of these interactions can be extracted from highlevel phenomena, such as decisions about life risks (e.g., Coulson \& Nunn, 1999).
Regarding the biological plausibility of a DST-informed approach, we have reviewed literature providing links between DST concepts and their neural counterparts. Furthermore, we have presented DST-informed neuroscientific methods to investigate decision making.

Therefore, we are optimistic about the potential of a DST-informed approach for providing the necessary links between behavior and neural substrates. Notably, this optimism is shared even by critics of dynamicism, granting that DST will "play an important role in our eventual understanding of cognition in terms of neurophysiology" (Grush, 1997, p. 241).

In line with the last argument, it has also been objected that dynamicism is typified by only metaphorical descriptions (Eliasmith, 1996; Summers, 1998).

To a certain degree, approaching a field with DST as a new tool set and an empirical guide (Newell, 1998) includes the extended use of analogous description (e.g., Thelen \& Smith, 1996). In fact, one strength of DST is the imaginative force of the analogies used. Nevertheless, analogies should be considered merely as starting points for the development of empirical constructs. The power of DST lies in offering a formal language for the description of the empirical constructs and the generation of models of nonlinear continuous processes across different levels of complexity (e.g., Erlhagen \& Schöner, 2002; Spivey, 2007). Therefore, the main advantage of a consistently DST-informed research program is the ability to physically substantiate its analogies (no scientific field is free of analogies; see Van Leeuwen, 2005); it offers a common language to span the different levels from the description of behavior to a model of its neural implementation (Beer, 1995; Clark, 1997).

Following up on the critique regarding the lack of biological plausibility and the use of metaphors, the criticism has been made that dynamicism fails to provide causal relationships and that dynamicist researchers are satisfied with general correlations of behavior and brain activity (see Van Leeuwen, 2005).

In line with the previous argument, it cannot be denied that initial approaches to a field, using DST, typically apply correlation analyses to confirm their hypotheses (e.g., Kelso et al., 1992). However, this is also true for nondynamical brain-behavior studies (see Stephan, 2004). Experiments at later stages show that more than correlational relationships can be found (e.g., Meyer-Lindenberg et al., 2002); with the concept of perturbations, DST-informed research has a tool at hand to investigate causal relationships.

More technically, the final theoretical objection concerns collective variables. It is unclear what collective variables refer to, precisely because they are collective. Furthermore, since the concepts are so abstract, there are still barriers to integration (Barton, 1994).

Taking dynamic concepts into account can, indeed, at first lead to the impression of a loss of explanatory power (see Spivey, 2007). Empirically, one can approach this problem in two different ways: a radical but very consistent way of thinking within the DST framework (Thelen \& Smith, 1996) and a more pragmatic way (van Geert \& Steenbeek, 2005). 
The first option clearly demands explorative studies to approach the phenomena of interest, in order to finally define the variables of interest (Granic \& Hollenstein, 2003). In the long run, hypothetical cognitive constructs and labels could be replaced by dynamical, physically grounded concepts (see Spivey, 2007; L. M. Ward, 2001). In the meantime, it seems worthwhile to choose the second, more conservative, but still promising option: trying to map the (e.g., cognitive) constructs of a domain onto DST concepts and collective variables, which is an approach that we have partly chosen for this work.

\section{The Practical Objection: Complexity}

The fact that DST originally came from mathematics and physics leads to three practical difficulties. In the first place, the physical DST concepts are very different from the concepts of an information-processing approach, demanding that DST-informed researchers describe classical problems in novel terms (Spivey, 2007). Second, a DSTinformed approach requires the researcher to deal with new and complex analytical methods (L. M. Ward, 2001). Third, realizing the potential of DST-informed empirical work requires thinking in the new framework in the first place in order to generate adequate questions and adequate paradigms to answer them (see Spivey, 2007).

To date, several introductions to DST have attempted to ease these burdens, ranging from general methodological introductions (e.g., F. D. Abraham, 1990; Beer, 2000; Boker \& Wenger, 2007; Heath, 2000; Spivey, 2007; Stewart \& Peregoy, 1983; L. M. Ward, 2001) to more specific literature for different subdisciplines (e.g., Granic \& Hollenstein, 2003; Kelso, 1995; Thelen \& Smith, 1996). With this article, we offer further assistance for researchers taking the first steps into this new mental model by introducing basic empirical strategies from a DST-informed perspective exemplarily applied to decision making.

\section{CONCLUSION}

In this article, we have identified current challenges to the interdisciplinary investigation of decision making in the field of neuroeconomics and have taken intertemporal choice as a representative example. We have introduced an empirical DST-informed approach to decision making, have developed a theoretical perspective on intertemporal choice, and have specified empirical strategies. We have argued that this approach could help to address the unresolved issues in intertemporal choice and have outlined the benefits of embracing a moderate DST-informed approach for neuroeconomics. Finally, we have answered possible objections to our DST-informed approach.

In summary, although adopting the principles of DST might be difficult at first, the aim of this article has been to inspire and encourage DST-informed empirical research as a valuable contribution to the interdisciplinary investigation of decision making.

\section{AUTHOR NOTE}

The first two authors contributed equally to this work. The collaboration between the authors was made possible by a grant from the Volkswagen
Foundation. This article was written as part of the "European Platform for Life Sciences, Mind Sciences, and the Humanities" initiative of the Volkswagen Foundation. We thank Martin Bleichner, Thomas Goschke, Fiona Mulvey, Hannes Ruge, Uta Wolfensteller, and the reviewers for their constructive and valuable comments. Correspondence concerning this article should be addressed to S. Scherbaum, Institut für Allgemeine Psychologie, Technische Universität Dresden, Zellescher Weg 17, 01062 Dresden, Germany (e-mail: stefan.scherbaum@web.de).

\section{REFERENCES}

Abraham, F. D. (1990). A visual introduction to dynamical systems theory for psychology. Santa Cruz, CA: Aerial Press.

Abraham, R., Gardini, L., \& Mira, C. (1997). Chaos in discrete dynamical systems: A visual introduction in 2 dimensions. Berlin: Springer.

AINSLIE, G. (1975). Specious reward: A behavioral theory of impulsiveness and impulse control. Psychological Bulletin, 82, 463-496.

Ainslie, G. (2005). Précis of breakdown of will. Behavioral \& Brain Sciences, 28, 635-650.

Almonte, F., Jirsa, V. K., Large, E. W., \& Tuller, B. (2005). Integration and segregation in auditory streaming. Physica D, 212, 137-159.

Arce, E., \& Santisteban, C. (2006). Impulsivity: A review. Psicothema, 18, 213-220.

Arthur, W. B. (1999). Complexity and the economy. Science, 284, 107-109.

Ashby, W. R. (1956). An introduction to cybernetics. London: Chapman \& Hall.

Ashby, W. R. (1960). Design for a brain: The origin of adaptive behaviour (2nd ed., rev.). London: Chapman \& Hall.

Athènes, S., SallagoÏty, I., Zanone, P.-G., \& Albaret, J.-M. (2004). Evaluating the coordination dynamics of handwriting. Human Movement Science, 23, 621-641.

AtKinson, J. W. (1957). Motivational determinants of risk-taking behavior. Psychological Review, 64, 359-372.

AUDI, R. (2006). Intuitionism, pluralism, and the foundations of ethics. In W. Sinnott-Armstrong \& M. Timmons (Eds.), Moral knowledge?: New readings in moral epistemology (pp. 101-136). Oxford: Oxford University Press.

Bardy, B. G., Oullier, O., Bootsma, R. J., \& Stoffregen, T. A. (2002). Dynamics of human postural transitions. Journal of Experimental Psychology: Human Perception \& Performance, 28, 499514.

BARTON, S. (1994). Chaos, self-organization, and psychology. American Psychologist, 49, 5-14.

Basar, E., Basar-Eroglu, C., Karakas, S., \& Schürmann, M. (2001). Gamma, alpha, delta, and theta oscillations govern cognitive processes. International Journal of Psychophysiology, 39, 241-248.

BECKER, G. S., \& MurPhy, K. M. (1988). A theory of rational addiction. Journal of Political Economy, 96, 675-700.

BeEr, R. D. (1995). A dynamical systems perspective on agentenvironment interaction. Artificial Intelligence, 72, 173-215.

BeER, R. D. (2000). Dynamical approaches to cognitive science. Trends in Cognitive Sciences, 4, 91-99.

BEER, R. D. (2003). The dynamics of active categorical perception in an evolved model agent. Adaptive Behavior, 11, 209-243.

Bélair, J., Glass, L., an der Heiden, U., \& Milton, J. (1995). Dynamical disease: Identification, temporal aspects and treatment strategies of human illness. Chaos, 5, 1-7.

Benhabib, J., Bisin, A., \& Schotter, A. (2004). Hyperbolic discounting and self-control: An experimental analysis. Unpublished manuscript, New York University.

Berns, G. S., Laibson, D., \& Loewenstein, G. (2007). Intertemporal choice - toward an integrative framework. Trends in Cognitive Sciences, 11, 482-488.

BICKEL, W. K., \& MARSCH, L. A. (2001). Toward a behavioral economic understanding of drug dependence: Delay discounting processes. $\mathrm{Ad}$ diction, 96, 73-86.

Bogacz, R. (2007). Optimal decision-making theories: Linking neurobiology with behaviour. Trends in Cognitive Sciences, 11, 118-125.

BoKer, S. M., \& Wenger, M. J. (EDS.) (2007). Data analytic techniques for dynamical systems. London: Erlbaum.

Botvinick, M. M., Braver, T. S., Barch, D. M., Carter, C. S., \& 
Cohen, J. D. (2001). Conflict monitoring and cognitive control. Psychological Review, 108, 624-652.

Braeutigam, S. (2005). Neuroeconomics-From neural systems to economic behaviour. Brain Research Bulletin, 67, 355-360.

Breakspear, M., Williams, L. M., \& Stam, C. J. (2004). A novel method for the topographic analysis of neural activity reveals formation and dissolution of "dynamic cell assemblies." Journal of Computational Neuroscience, 16, 49-68.

Bressler, S. L., \& Kelso, J. A. S. (2001). Cortical coordination dynamics and cognition. Trends in Cognitive Sciences, 5, 26-36.

Busemeyer, J. R., Jessup, R. K., Johnson, J. G., \& Townsend, J. T. (2006). Building bridges between neural models and complex decision making behaviour. Neural Networks, 19, 1047-1058.

Calhoun, V. D., Adali, T., Pearlson, G. D., \& Pekar, J. J. (2001). A method for making group inferences from functional MRI data using independent component analysis. Human Brain Mapping, 14, 140-151.

Camerer, C., Loewenstein, G., \& Prelec, D. (2005). Neuroeconomics: How neuroscience can inform economics. Journal of Economic Literature, 43, 9-64.

CARDinal, R. N. (2006). Neural systems implicated in delayed and probabilistic reinforcement. Neural Networks, 19, 1277-1301.

Chabris, C. F., Laibson, D. I., \& Schuldt, J. P. (2008). Intertemporal choice. In S. N. Durlauf \& L. E. Blume (Eds.), The new Palgrave dictionary of economics (2nd ed., pp. 536-542). London: Palgrave Macmillan.

Churchill, E. (2008). A dynamic systems account of learning a word: From ecology to form relations. Applied Linguistics, 29, 339-358.

Clark, A. (1997). The dynamical challenge. Cognitive Science, 21, 461-481.

Clark, A. (1999). An embodied cognitive science? Trends in Cognitive Sciences, 3, 345-351.

Clark, A., \& Toribio, J. (1994). Doing without representing? Synthese, 101, 401-431.

Clearfield, M. W., Diedrich, F. J., Smith, L. B., \& Thelen, E. (2006). Young infants reach correctly in A-not-B tasks: On the development of stability and perseveration. Infant Behavior \& Development, 29, 435-444.

Coulson, M., \& Nunn, S. (1999). The detection of catastrophe flags in personally relevant decisions. In W. Tschacher \& J.-P. Dauwalder (Eds.), Dynamics, synergetics, autonomous agents: Nonlinear systems approaches to cognitive psychology and cognitive science (pp. 241255). Singapore: World Scientific.

Critchfield, T. S., \& Kollins, S. H. (2001). Temporal discounting: Basic research and the analysis of socially important behavior. Journal of Applied Behavior Analysis, 34, 101-122.

Debener, S., Ullsperger, M., Siegel, M., Fiehler, K., von Cramon, D. Y., \& ENGEL, A. K. (2005). Trial-by-trial coupling of concurrent electroencephalogram and functional magnetic resonance imaging identifies the dynamics of performance monitoring. Journal of Neuroscience, 25, 11730-11737.

de Bot, K., Lowie, W., \& Verspoor, M. (2007). A dynamic systems theory approach to second language acquisition. Bilingualism: Language \& Cognition, 10, 7-21.

Deco, G., \& Rolls, E. T. (2003). Attention and working memory: A dynamical model of neuronal activity in the prefrontal cortex. European Journal of Neuroscience, 18, 2374-2390.

Delignières, D., Fortes, M., \& Ninot, G. (2004). The fractal dynamics of self-esteem and physical self. Nonlinear Dynamics in Psychology \& Life Sciences, 8, 479-510.

Delorme, A., \& MAKeIG, S. (2004). EEGLAB: An open source toolbox for analysis of single-trial EEG dynamics including independent component analysis. Journal of Neuroscience Methods, 134, 9-21.

Delorme, A., Makeig, S., Fabre-Thorpe, M., \& Sejnowski, T. (2002). From single-trial EEG to brain area dynamics. Neurocomputing, 44, 1057-1064.

Dennett, D. C. (1971). Intentional systems. Journal of Philosophy, 68, 87-106.

Diederich, A., \& Busemeyer, J. R. (1999). Conflict and the stochasticdominance principle of decision making. Psychological Science, 10, 353-359.

DoyA, K. (2008). Modulators of decision making. Nature Neuroscience, 11, 410-416.
Eliasmith, C. (1996). The third contender: A critical examination of the dynamicist theory of cognition. Philosophical Psychology, 9, 441-463.

Elman, J. L. (2004). An alternative view of the mental lexicon. Trends in Cognitive Sciences, 8, 301-306.

Engel, A. K., Fries, P., \& Singer, W. (2001). Dynamic predictions: Oscillations and synchrony in top-down processing. Nature Reviews Neuroscience, 2, 704-716.

ERLhagen, W., \& SchöNER, G. (2002). Dynamic field theory of movement preparation. Psychological Review, 109, 545-572.

Evenden, J. L. (1999). Varieties of impulsivity. Psychopharmacology, 146, 348-361.

FARRAR, W. T., \& VAN ORdEN, G. C. (2001). Errors as multistable response options. Nonlinear Dynamics, Psychology, \& Life Sciences, 5, 223-265.

Fellows, L. K. (2004). The cognitive neuroscience of human decision making: A review and conceptual framework. Behavioral \& Cognitive Neuroscience Reviews, 3, 159-172.

Fellows, L. K., \& FARAH, M. J. (2005). Different underlying impairments in decision-making following ventromedial and dorsolateral frontal lobe damage in humans. Cerebral Cortex, 15, 58-63.

FishbuRn, P. C. (1981). Transitive measurable utility. Murray Hill, NJ: Bell Telephone Laboratories.

Frederick, S., Loewenstein, G., \& O’Donoghue, T. (2002). Time discounting and time preference: A critical review. Journal of Economic Literature, 40, 351-401.

Freeman, W. J. (2003). A neurobiological theory of meaning in perception. Neural Networks, 2, 1371-1378.

FrISTON, K. J. (1998). Modes or models: A critique on independent component analysis for fMRI. Trends in Cognitive Sciences, 2, 373-375.

FudEnBERG, D., \& LEVINE, D. K. (2006). A dual-self model of impulse control. American Economic Review, 96, 1449-1476.

GILDEN, D. L. (1997). Fluctuations in the time required for elementary decisions. Psychological Science, 8, 296-301.

GiLmoRe, R. (1981). Catastrophe theory for scientists and engineers. New York: Wiley.

Giraudo, M.-D., \& Pailhous, J. (1999). Dynamic instability of visuospatial images. Journal of Experimental Psychology: Human Perception \& Performance, 25, 1495-1516.

Glimcher, P. W., Dorris, M. C., \& Bayer, H. M. (2005). Physiological utility theory and the neuroeconomics of choice. Games \& Economic Behavior, 52, 213-256.

Glimcher, P. W., Kable, J., \& Louie, K. (2007). Neuroeconomic studies of impulsivity: Now or just as soon as possible? American Economic Review, 97, 142-147.

Glimcher, P. W., \& Rustichini, A. (2004). Neuroeconomics: The consilience of brain and decision. Science, 306, 447-452.

Gold, J. I., \& Shadlen, M. N. (2007). The neural basis of decision making. Annual Review of Neuroscience, 30, 535-574.

GoldberG, J., \& MARKoczy, L. (2000). Complex rhetoric and simple games. Emergence, 2, 72-100.

Grace, R. C. (1999). The matching law and amount-dependent exponential discounting as accounts of self-control choice. Journal of the Experimental Analysis of Behavior, 71, 27-44.

Granic, I., \& Hollenstein, T. (2003). Dynamic systems methods for models of developmental psychopathology. Development \& Psychopathology, 15, 641-669.

Granic, I., \& Patterson, G. R. (2006). Toward a comprehensive model of antisocial development: A dynamic systems approach. Psychological Review, 113, 101-131.

Green, L., \& Myerson, J. (2004). A discounting framework for choice with delayed and probabilistic rewards. Psychological Bulletin, 130, 769-792.

Grush, R. (1997). Yet another design for a brain? Philosophical Psychology, 10, 233-242.

GuAstello, S. J., \& BOND, R. W., JR. (2007). The emergence of leadership in coordination-intensive groups. Nonlinear Dynamics, Psychology, \& Life Sciences, 11, 91-117.

Guastello, S. J., Pincus, D., \& Gunderson, P. R. (2006). Electrodermal arousal between participants in a conversation: Nonlinear dynamics and linkage effects. Nonlinear Dynamics, Psychology, \& Life Sciences, 10, 365-399.

Gul, F., \& Pesendorfer, W. (2001). Temptation and self-control. Econometrica, 69, 1403-1435. 
HAKEN, H. (2004). Synergetics: Introduction and advanced topics. Berlin: Springer.

HARE, R. M. (1981). Moral thinking. Oxford: Oxford University Press.

Harvey, I., Di Paolo, E., Wood, R., Quinn, M., \& Tuci, E. (2005). Evolutionary robotics: A new scientific tool for studying cognition. Artificial Life, 11, 79-98.

Hastie, R., \& Dawes, R. M. (2001). Rational choice in an uncertain world: The psychology of judgment and decision making. New York: Sage.

Heath, R. A. (2000). Nonlinear dynamics: Techniques and applications in psychology. Mahwah, NJ: Erlbaum.

Hinton, S. C., \& MEcK, W. H. (2004). Frontal-striatal circuitry activated by human peak-interval timing in the supra-seconds range. Cognitive Brain Research, 21, 171-182.

Holt, D. D., Green, L., \& Myerson, J. (2003). Is discounting impulsive? Evidence from temporal and probability discounting in gambling and non-gambling college students. Behavioural Processes, 64, 355-367.

Hume, D. (1739). A treatise of human nature (rev. ed.; L. A. Selby-Bigge, Ed.). Oxford: Oxford University Press, Clarendon Press.

IsEN, A. M. (2000). Positive affect and decision making. In M. Lewis \& J. M. Haviland-Jones (Eds.), Handbook of emotions (2nd ed., pp. 417437). New York: Guilford.

Jaeger, H., \& Christaller, T. (1998). Dual dynamics: Designing behavior systems for autonomous robots. Artificial Life \& Robotics, 2 , 108-112.

Johnson, J. S., Spencer, J. P., \& Schöner, G. (2006, July). A dynamic neural field theory of multi-item visual working memory and change detection. Paper presented at the 28th Annual Conference of the Cognitive Science Society (CogSci 2006), Vancouver, BC.

Jonker, C. M., Snoep, J. L., Treur, J., Westerhoff, H. V., \& WiJnGAARDS, W. C. A. (2002). Embodied intentional dynamics of bacterial behaviour. In Proceedings of the First International Joint Conference on Autonomous Agents and Multiagent Systems: Part 1 (pp. 465-466). New York: ACM Press.

JuARrero, A. (1999). Dynamics in action: Intentional behavior as a complex system. Cambridge, MA: MIT Press.

Jung, T. P., Makeig, S., McKeown, M. J., Bell, A. J., Lee, T. W., \& SeJNowsKI, T. J. (2001). Imaging brain dynamics using independent component analysis. Proceedings of the IEEE, 89, 1107-1122.

Kable, J. W., \& Glimcher, P. W. (2007). The neural correlates of subjective value during intertemporal choice. Nature Neuroscience, 10, $1625-1633$.

Kahneman, D. (2003). Maps of bounded rationality: Psychology for behavioral economics. American Economic Review, 93, 1449-1475.

Kahneman, D., \& Tversky, A. (1979). Prospect theory: An analysis of decision under risk. Econometrica, 47, 263-292.

Kalenscher, T., \& Pennartz, C. M. A. (2008). Is a bird in the hand worth two in the future? The neuroeconomics of intertemporal decision-making. Progress in Neurobiology, 84, 284-315.

Kanai, R., Moradi, F., Shimojo, S., \& Verstraten, F. A. J. (2005). Perceptual alternation induced by visual transients. Perception, 34, 803-822.

Kauffman, S. A. (1993). The origins of order: Self-organization and selection in evolution. Oxford: Oxford University Press.

KeiJzer, F. A., \& Bem, S. (1996). Behavioral systems interpreted as autonomous agents and as coupled dynamic systems: A criticism. Philosophical Psychology, 9, 323-346.

Kelly, A., Heathcote, A., Heath, R., \& Longstaff, M. (2001). Response-time dynamics: Evidence for linear and low-dimensional nonlinear structure in human choice sequences. Quarterly Journal of Experimental Psychology, 54A, 805-840.

KeLso, J. A. S. (1995). Dynamic patterns: The self-organization of brain and behavior. Cambridge, MA: MIT Press.

Kelso, J. A. S. (2000). Principles of dynamic pattern formation and change for a science of human behavior. In L. R. Bergman, R. B. Cairns, L.-G. Nilsson, \& L. Nystedt (Eds.), Developmental science and the holistic approach (pp. 63-83). London: Erlbaum.

Kelso, J. A. S., Bressler, S. L., Buchanan, S., DeGuzman, G. C., Ding, M., Fuchs, A., \& Holroyd, T. (1992). A phase transition in human brain and behavior. Physics Letters A, 169, 134-144.

Kelso, J. A. S., Case, P., Holroyd, T., Horvath, E., Raczaszek, J., Tuller, B., \& Ding, M. (1995). Multistability and metastability in perceptual and brain dynamics. In P. Kruse \& M. Stadler (Eds.), Ambiguity in mind and nature: Multistable cognitive phenomena (pp. 159184). Berlin: Springer.

Kelso, J. A. S., \& Zanone, P.-G. (2002). Coordination dynamics of learning and transfer across different effector systems. Journal of Experimental Psychology: Human Perception \& Performance, 28, 776-797.

Kenning, P., \& Plassmann, H. (2005). NeuroEconomics: An overview from an economic perspective. Brain Research Bulletin, 67, 343-354.

Kerick, S. E., Hatfield, B. D., \& Allender, L. E. (2007). Eventrelated cortical dynamics of soldiers during shooting as a function of varied task demand. Aviation, Space, \& Environmental Medicine, 78, 153-164.

KIRBY, K. N. (1997). Bidding on the future: Evidence against normative discounting of delayed rewards. Journal of Experimental Psychology: General, 126, 54-70.

Kirby, K. N., \& Herrnstein, R. J. (1995). Preference reversal due to myopia of delayed reward. Psychological Science, 6, 83-89.

Knutson, B., \& CoOper, J. C. (2005). Functional magnetic resonance imaging of reward prediction. Current Opinion in Neurology, 18, 411-417.

Kostrubiec, V., Tallet, J., \& Zanone, P.-G. (2006). How a new behavioral pattern is stabilized with learning determines its persistence and flexibility in memory. Experimental Brain Research, 170, 238-244.

Kozma, R., Harter, D., \& Achunala, S. (2007). Dynamical aspects of behavior generation under constraints. Cognitive Neurodynamics, 1, 213-223

Lachaux, J.-P., Rodriguez, E., Le Van Quyen, M., Lutz, A., MarTINERIE, J., \& VARELA, F. J. (2000). Studying single-trials of phase synchronous activity in the brain. International Journal of Bifurcation \& Chaos, 10, 2429-2439.

Lachaux, J.-P., Rodriguez, E., Martinerie, J., \& Varela, F. J. (1999). Measuring phase synchrony in brain signals. Human Brain Mapping, 8, 194-208.

Lagarde, J., \& Kelso, J. A. S. (2006). Binding of movement, sound and touch: Multimodal coordination dynamics. Experimental Brain Research, 173, 673-688.

Lagorio, C. H., \& Madden, G. J. (2005). Delay discounting of real and hypothetical rewards III: Steady-state assessments, forced-choice trials, and all real rewards. Behavioural Processes, 69, 173-187.

LAIBSON, D. (1997). Golden eggs and hyperbolic discounting. Quarterly Journal of Economics, 112, 443-477.

Lane, S. D., Cherek, D. R., Pietras, C. J., \& Tcheremissine, O. V. (2003). Measurement of delay discounting using trial-by-trial consequences. Behavioural Processes, 64, 287-303.

LEVEN, S. J., \& LeVINE, D. S. (1996). Multiattribute decision making in context: A dynamic neural network methodology. Cognitive Science, 20, 271-299.

LEWIS, M. D. (2000). The promise of dynamic systems approaches for an integrated account of human development. Child Development, 71, 36-43.

LEWIS, M. D. (2005). Bridging emotion theory and neurobiology through dynamic systems modeling. Behavioral \& Brain Sciences, 28, 169-194.

Li, P., Farkas, I., \& MacWhinney, B. (2004). Early lexical development in a self-organizing neural network. Neural Networks, 17, 1345-1362.

Loewenstein, G. F. (1987). Anticipation and the valuation of delayed consumption. Economic Journal, 97, 666-684.

Loewenstein, G. F. (1996). Out of control: Visceral influences on behavior. Organizational Behavior \& Human Decision Processes, 65, 272-292.

Loewenstein, G. F., \& Prelec, D. (1991). Negative time preference. American Economic Review, 81, 347-352.

Loewenstein, G. F., \& Prelec, D. (1992). Anomalies in intertemporal choice: Evidence and an interpretation. Quarterly Journal of Economics, 107, 573-597.

Loewenstein, G. F., \& Prelec, D. (1993). Preferences for sequences of outcomes. Psychological Review, 100, 91-108.

Loewenstein, G. F., Rick, S., \& Cohen, J. D. (2008). Neuroeconomics. Annual Review of Psychology, 59, 647-672.

LOH, M., \& DECO, G. (2005). Cognitive flexibility and decision-making 
in a model of conditional visuomotor associations. European Journal of Neuroscience, 22, 2927-2936.

Loh, M., Pasupathy, A., Miller, E. K., \& Deco, G. (2008). Neurodynamics of the prefrontal cortex during conditional visuomotor associations. Journal of Cognitive Neuroscience, 20, 421-431.

Madden, G. J., BegotKa, A. M., Raiff, B. R., \& Kastern, L. L. (2003). Delay discounting of real and hypothetical rewards. Experimental \& Clinical Psychopharmacology, 11, 139-145.

Magnuson, J. S. (2005). Moving hand reveals dynamics of thought Proceedings of the National Academy of Sciences, 102, 9995-9996.

Makeig, S., Debener, S., Onton, J., \& Delorme, A. (2004). Mining event-related brain dynamics. Trends in Cognitive Sciences, $\mathbf{8}$, 204-210.

Makeig, S., Delorme, A., Westerfield, M., Jung, T. P., Townsend, J., Courchesne, E., \& Sejnowski, T. J. (2004). Electroencephalographic brain dynamics following manually responded visual targets. PLoS Biology, 2, 747-762.

Maturana, H. R., \& Varela, F. J. (1987). Tree of knowledge: The biological roots of human understanding. Boston: New Science Library.

McClelland, J. L., \& Rumelhart, D. E. (1987). Parallel distributed processing: Vol. 2. Psychological and biological models. Cambridge, MA: MIT Press.

McClune, S. M., Ericson, K. M., Laibson, D. I., Loewenstein, G., \& CoHen, J. D. (2007). Time discounting for primary rewards. Journal of Neuroscience, 27, 5796-5804.

McClure, S. M., Laibson, D. I., Loewenstein, G., \& Cohen, J. D. (2004). Separate neural systems value immediate and delayed monetary rewards. Science, 306, 503-507.

McDougall, K. (2006). Dynamic features of speech and the characterization of speakers: Towards a new approach using formant frequencies. International Journal of Speech Language \& the Law, 13, 89-126.

Melloni, L., Molina, C., Peña, M., Torres, D., Singer, W., \& RodRIGUEZ, E. (2007). Synchronization of neural activity across cortical areas correlates with conscious perception. Journal of Neuroscience, 27, 2858-2865.

Metcalfe, J., \& Mischel, W. (1999). A hot/cool-system analysis of delay of gratification: Dynamics of willpower. Psychological Review, 106, 3-19.

Meyer-Lindenberg, A., Ziemann, U., Hajak, G., Cohen, L., \& BerMAN, K. F. (2002). Transitions between dynamical states of differing stability in the human brain. Proceedings of the National Academy of Sciences, 99, 10948-10953.

Mitchener, W. G., \& NowaK, M. A. (2004). Chaos and language. Proceedings of the Royal Society B, 271, 701-704.

Montague, P. R., \& Berns, G. S. (2002). Neural economics and the biological substrates of valuation. Neuron, 36, 265-284.

Montague, P. R., King-Casas, B., \& Cohen, J. D. (2006). Imaging valuation models in human choice. Annual Review of Neuroscience, 29, 417-448.

Müller, M. M., Andersen, S. K., \& KeIL, A. (2008). Time course of competition for visual processing resources between emotional pictures and foreground task. Cerebral Cortex, 18, 1892-1899.

Müller, M. M., Teder-Sälejärvi, W., \& Hillyard, S. A. (1998). The time course of cortical facilitation during cued shifts of spatial attention. Nature Neuroscience, 1, 631-634.

Murphy, J. G., Vuchinich, R. E., \& Simpson, C. A. (2001). Delayed reward and cost discounting. Psychological Record, 51, 571-588.

Myerson, J., \& Green, L. (1995). Discounting of delayed rewards: Models of individual choice. Journal of the Experimental Analysis of Behavior, 64, 263.

Naqvi, N., Shiv, B., \& Bechara, A. (2006). The role of emotion in decision making: A cognitive neuroscience perspective. Current Directions in Psychological Science, 15, 260-264.

Nenadic, I., Gaser, C., Volz, H. P., Rammsayer, T., Häger, F., \& SAUER, H. (2003). Processing of temporal information and the basal ganglia: New evidence from fMRI. Experimental Brain Research, 148, 238-246.

Newell, K. M. (1998). Action and ecological psychology: A winter's view from Summers. In J. P. Piek (Ed.), Motor behavior and human skill: A multidisciplinary approach (pp. 410-412). Leeds, U.K.: Human Kinetics.
O'Doherty, J. P., Hampton, A., \& Kim, H. (2007). Model-based fMRI and its application to reward learning and decision making. In B. W. Balleine, K. Doya, J. O’Doherty, \& M. Sakagami (Eds.), Reward and decision making in corticobasal ganglia networks (Annals of the New York Academy of Sciences, Vol. 1104, pp. 35-53). New York: New York Academy of Sciences.

Odum, A. L. (2006). Interval timing: The current status. Behavioural Processes, 71, 75-76.

Odum, A. L., \& RaINAUd, C. P. (2003). Discounting of delayed hypothetical money, alcohol, and food. Behavioural Processes, 64, 305-313.

Onton, J., Delorme, A., \& Makeig, S. (2005). Frontal midline EEG dynamics during working memory. NeuroImage, 27, 341-356.

Oullier, O., \& Kelso, J. A. (2006). Neuroeconomics and the metastable brain. Trends in Cognitive Sciences, 10, 353-354.

Phelps, E. S., \& Pollak, R. A. (1968). On second-best national saving and game-equilibrium growth. Review of Economic Studies, 35, 185-199.

Philiastides, M. G., Ratcliff, R., \& Sajda, P. (2006). Neural representation of task difficulty and decision making during perceptual categorization: A timing diagram. Journal of Neuroscience, 26, 8965.

Philiastides, M. G., \& SAJdA, P. (2006). Temporal characterization of the neural correlates of perceptual decision making in the human brain. Cerebral Cortex, 16, 509-518.

Platt, M. L., \& Glimcher, P. W. (1999). Neural correlates of decision variables in the parietal cortex. Nature, 400, 233-238.

Pressing, J., \& Jolley-Rogers, G. (1997). Spectral properties of human cognition and skill. Biological Cybernetics, 76, 339-347.

Proekt, A., Brezina, V., \& Weiss, K. R. (2004). Dynamical basis of intentions and expectations in a simple neuronal network. Proceedings of the National Academy of Sciences, 101, 9447-9452.

Queller, S. (2002). Stereotype change in a recurrent network. Personality \& Social Psychology Review, 6, 295-303.

Rachlin, H. (1971). On the tautology of the matching law. Journal of the Experimental Analysis of Behavior, 15, 249-251.

RACHLIN, H., \& RAINERI, A. (1992). Irrationality, impulsiveness, and selfishness as discount reversal effects. In G. Loewenstein \& J. Elster (Eds.), Choice over time (pp. 93-118). New York: Russell Sage Foundation.

RAFFone, A., \& Wolters, G. (2001). A cortical mechanism for binding in visual working memory. Journal of Cognitive Neuroscience, 13, 766-785.

Read, D., Frederick, S., Orsel, B., \& Rahman, J. (2005). Four score and seven years from now: The date/delay effect in temporal discounting. Management Science, 51, 1326-1335.

REYNOLDS, B. (2006). A review of delay-discounting research with humans: Relations to drug use and gambling. Behavioural Pharmacology, 17, 651-667.

Reynolds, B., Ortengren, A., Richards, J. B., \& De Wit, H. (2006). Dimensions of impulsive behavior: Personality and behavioral measures. Personality \& Individual Differences, 40, 305-315.

Richards, D. (1990). Is strategic decision making chaotic? Behavioral Science, 35, 219-232.

Richards, D., \& HAYs, J. C. (1998). Navigating a nonlinear environment: An experimental study of decision making in a chaotic setting. Journal of Economic Behavior \& Organization, 35, 281-308.

Rodriguez, E., George, N., Lachaux, J.-P., Martinerie, J., ReNaUlt, B., \& Varela, F. J. (1999). Perception's shadow: Long-distance synchronization of human brain activity. Nature, 397, 430-433.

Roesch, M. R., Calu, D. J., Burke, K. A., \& Schoenbaum, G. (2007). Should I stay or should I go? Transformation of time-discounted rewards in orbitofrontal cortex and associated brain circuits. In B. W. Balleine, K. Doya, J. O'Doherty, \& M. Sakagami (Eds.), Reward and decision making in corticobasal ganglia networks (Annals of the New York Academy of Sciences, Vol. 1104, pp. 21-34). New York: New York Academy of Sciences.

Rosser, J. B., JR. (1999). On the complexities of complex economic dynamics. Journal of Economic Perspectives, 13, 169-192.

Rosser, J. B., JR. (2007). The rise and fall of catastrophe theory applications in economics: Was the baby thrown out with the bathwater? Journal of Economic Dynamics \& Control, 31, 3255-3280.

RUECKL, J. G. (2002). The dynamics of visual word recognition. Ecological Psychology, 14, 5-19. 
RupPIN, E. (2002). Evolutionary autonomous agents: A neuroscience perspective. Nature Reviews Neuroscience, 3, 132-141.

Samuelson, P. A. (1937). A note on measurement of utility. Review of Economic Studies, 4, 155-161.

SAnfey, A. G. (2007). Decision neuroscience: New directions in studies of judgment and decision making. Current Directions in Psychological Science, 16, 151-155.

Sanfey, A. G., Loewenstein, G., McClure, S. M., \& Cohen, J. D. (2006). Neuroeconomics: Cross-currents in research on decisionmaking. Trends in Cognitive Sciences, 10, 108-116.

SCANlon, T. (1998). What we owe to each other. Cambridge, MA: Belknap Press of Harvard University Press.

Schöner, G., \& Thelen, E. (2006). Using dynamic field theory to rethink infant habituation. Psychological Review, 113, 273-299.

Schultz, W. (1998). Predictive reward signal of dopamine neurons. Journal of Neurophysiology, 80, 1-27.

Schwarz, N. (2000). Emotion, cognition, and decision making. Cognition \& Emotion, 14, 433-440.

Schweighofer, N., Shishida, K., Han, C. E., OKamoto, Y., TanaKa, S. C., YamawaKi, S., \& Doya, K. (2006). Humans can adopt optimal discounting strategy under real-time constraints. PLoS Computational Biology, 2, e152.

Schweighofer, N., Tanaka, S. C., \& Doya, K. (2007). Serotonin and the evaluation of future rewards: Theory, experiments, and possible neural mechanisms. In B. W. Balleine, K. Doya, J. O'Doherty, \& M. Sakagami (Eds.), Reward and decision making in corticobasal ganglia networks (Annals of the New York Academy of Sciences, Vol. 1104, pp. 289-300). New York: New York Academy of Sciences.

Simon, H. A. (1965). Administrative decision making. Public Administration Review, 25, 31-37.

Sozou, P. D. (1998). On hyperbolic discounting and uncertain hazard rates. Proceedings of the Royal Society B, 265, 2015-2020.

SPIVEy, M. J. (2007). The continuity of mind. Oxford: Oxford University Press.

Spivey, M. J., \& Dale, R. (2004). On the continuity of mind: Toward a dynamical account of cognition. In B. H. Ross (Ed.), The psychology of learning and motivation: Advances in research and theory (Vol. 45, pp. 87-142). Amsterdam: Elsevier.

Spivey, M. J., \& Dale, R. (2006). Continuous dynamics in real-time cognition. Current Directions in Psychological Science, 15, 207-211.

StePHAN, K. E. (2004). On the role of general system theory for functional neuroimaging. Journal of Anatomy, 205, 443-470.

Stewart, I. N., \& Peregoy, P. L. (1983). Catastrophe theory modeling in psychology. Psychological Bulletin, 94, 336-362.

Sugrue, L. P., Corrado, G. S., \& Newsome, W. T. (2005). Choosing the greater of two goods: Neural currencies for valuation and decision making. Nature Reviews Neuroscience, 6, 363-375.

Summers, J. J. (1998). Has ecological psychology delivered what it promised? In J. P. Piek (Ed.), Motor behavior and human skill: A multidisciplinary approach (pp. 385-402). Leeds, U.K.: Human Kinetics.

Svyantek, D. J., DeShon, R. P., \& Siler, M. T. (1991). The illusion of certainty: A catastrophe model of decision framing. Current Psychology, 10, 199-209.

Tabor, W., \& Tanenhaus, M. K. (1999). Dynamical models of sentence processing. Cognitive Science, 23, 491-515.

TAKAHASHI, T. (2005). Loss of self-control in intertemporal choice may be attributable to logarithmic time-perception. Medical Hypotheses, 65, 691-693.

Takahashi, T., Ikeda, K., \& Hasegawa, T. (2007). A hyperbolic decay of subjective probability of obtaining delayed rewards. Behavioral \& Brain Functions, 3, 52.

TAKahashi, T., Oono, H., \& Radford, M. H. B. (2008). Psychophysics of time perception and intertemporal choice models. Physica A, 387, 2066-2074.

TanaKa, S. C., Doya, K., OKada, G., Ueda, K., Окамотo, Y., \& YAMAWAKI, S. (2004). Prediction of immediate and future rewards differentially recruits cortico-basal ganglia loops. Nature Neuroscience, 7, 887-893.

Tanaka, S. C., Samejima, K., OKada, G., Ueda, K., OKamoto, Y., YAMAWAKI, S., \& Doya, K. (2006). Brain mechanism of reward prediction under predictable and unpredictable environmental dynamics. Neural Networks, 19, 1233-1241.

Tanaka, S. C., Schweighofer, N., Asahi, S., Shishida, K., OKa- мото, Y., YAmawaKi, S., \& Doya, K. (2007). Serotonin differentially regulates short- and long-term prediction of rewards in the ventral and dorsal striatum. PLOS ONE, 2, e1333.

Thagard, P., \& Nerb, J. (2002). Emotional gestalts: Appraisal, change, and the dynamics of affect. Personality \& Social Psychology Review, 6, 274-282.

Thaler, R. H., \& Shefrin, H. M. (1981). An economic theory of selfcontrol. Journal of Political Economy, 89, 392-406.

Thelen, E. (1995). Time-scale dynamics and the development of an embodied cognition. In R. F. Port \& T. van Gelder (Eds.), Mind as motion: Explorations in the dynamics of cognition (pp. 69-101). Cambridge, MA: MIT Press.

Thelen, E., \& Bates, E. (2003). Connectionism and dynamic systems: Are they really different? Developmental Science, 6, 378-391.

Thelen, E., Schöner, G., Scheier, C., \& Smith, L. B. (2001). The dynamics of embodiment: A field theory of infant perseverative reaching. Behavioral \& Brain Sciences, 24, 1-34.

Thelen, E., \& Smith, L. B. (1996). A dynamic systems approach to the development of cognition and action. Cambridge, MA: MIT Press.

Thelen, E., Ulrich, B. D., \& WolfF, P. H. (1991). Hidden skills: A dynamic systems analysis of treadmill stepping during the first year. Monographs of the Society for Research in Child Development, 56, 1-103.

Townsend, J. T., \& Busemeyer, J. R. (1989). Approach-avoidance: Return to dynamic decision behavior. In C. Izawa (Ed.), Current issues in cognitive processes: The Tulane Flowerree Symposium on Cognition (pp. 107-133). Hillsdale, NJ: Erlbaum.

Townsend, J. T., \& Busemeyer, J. [R.] (1995). Dynamic representation of decision-making. In R. F. Port \& T. van Gelder (Eds.), Mind as motion: Explorations in the dynamics of cognition (pp. 101-120). Cambridge, MA: MIT Press.

Tschacher, W., Dauwalder, J.-P., \& Haken, H. (2003). Selforganizing systems show apparent intentionality. In W. Tschacher \& J.-P. Dauwalder (Eds.), The dynamical systems approach to cognition: Concepts and empirical paradigms based on self-organization, embodiment, and coordination dynamics (pp. 183-200). River Edge, NJ: World Scientific.

Usher, M., \& McClelland, J. L. (2004). Loss aversion and inhibition in dynamical models of multialternative choice. Psychological Review, 111, 757-769.

Vallacher, R. R., Read, S. J., \& NowaK, A. (2002). The dynamical perspective in personality and social psychology. Personality \& Social Psychology Review, 6, 264-273.

van Geert, P., \& Steenbeek, H. (2005). Explaining after by before: Basic aspects of a dynamic systems approach to the study of development. Developmental Review, 25, 408-442.

VAN GELDER, T. (1998). The dynamical hypothesis in cognitive science. Behavioral \& Brain Sciences, 21, 615-628.

van Gelder, T., \& PorT, R. F. (1995). It's about time: An overview of the dynamical approach to cognition. In R. F. Port \& T. van Gelder (Eds.), Mind as motion: Explorations in the dynamics of cognition (pp. 1-44). Cambridge, MA: MIT Press.

VAN LeEUwen, M. (2005). Questions for the dynamicist: The use of dynamical systems theory in the philosophy of cognition. Minds \& Machines, 15, 271-333.

van Orden, G. C., Holden, J. G., \& Turvey, M. T. (2003). Selforganization of cognitive performance. Journal of Experimental Psychology: General, 132, 331-350.

VAN ROOIJ, I., \& BONGERs, R. M. (2000). The dynamics of simple prediction: Judging reachability. In L. R. Gleitman \& A. K. Joshi (Eds.), Proceedings of the Twenty-Second Annual Conference of the Cognitive Science Society (pp. 535-540). Mahwah, NJ: Erlbaum.

Varela, F., Lachaux, J.-P., Rodriguez, E., \& Martinerie, J. (2001). The brainweb: Phase synchronization and large-scale integration. $\mathrm{Na}$ ture Reviews Neuroscience, 2, 229-239.

von Neumann, J., \& Morgenstern, O. (1944). Theory of games and economic behavior. Princeton, NJ: Princeton University Press.

Wallace, R. J. (1990). How to argue about practical reason. Mind, 99, 355-385.

WANG, X.-J. (2002). Probabilistic decision making by slow reverberation in cortical circuits. Neuron, 36, 955-968.

WARD, L. M. (2001). Dynamical cognitive science. Cambridge, MA: MIT Press. 
WARD, R., \& WARD, R. (2006). Cognitive conflict without explicit conflict monitoring in a dynamical agent. Neural Networks, 19, 1430-1436.

Warren, K., Sprott, J. C., \& Hawkins, R. C. (2002). The spirit is willing: Nonlinearity, bifurcations, and mental control. Nonlinear Dynamics, Psychology, \& Life Sciences, 6, 55-70.

Weiss, S., \& Mueller, H. M. (2003). The contribution of EEG coherence to the investigation of language. Brain \& Language, 85, 325-343.

West, R. L., \& LebIERE, C. (2001). Simple games as dynamic, coupled systems: Randomness and other emergent properties. Cognitive Systems Research, 1, 221-239.

Wilimzig, C., \& ScHöNeR, G. (2005, July). The emergence of stimulusresponse associations from neural activation fields: Dynamic field theory. Poster presented at the 27th Annual Conference of the Cognitive Science Society, Stresa, Italy.

Wittmann, M., Leland, D. S., \& Paulus, M. P. (2007). Time and decision making: Differential contribution of the posterior insular cortex and the striatum during a delay discounting task. Experimental Brain Research, 179, 643-653.

Wittmann, M., \& Paulus, M. P. (2007). Decision making, impulsivity and time perception. Trends in Cognitive Sciences, 12, 7-12.

Wong, K.-F., HuK, A. C., Shadlen, M. N., \& WANG, X.-J. (2007). Neural circuit dynamics underlying accumulation of time-varying evidence during perceptual decision making. Frontiers in Computational Neuroscience [Online journal], 1(6).

Yarkoni, T., Braver, T. S., Gray, J. R., \& Green, L. (2005). Prefrontal brain activity predicts temporally extended decision-making behavior. Journal of the Experimental Analysis of Behavior, 84, 537-554.

ZAK, P. J. (2004). Neuroeconomics. Philosophical Transactions of the Royal Society, 359, 1737-1748.

\section{NOTES}

1. The exponential discount function (from Green \& Myerson, 2004) is $V=A * \mathrm{e}^{-b D}$ ( $V$ is the subjective value of the reward, $A$ is its amount, $D$ is the delay, and $b$ is the discounting parameter governing the rate of discounting).

2.The hyperbolic discounting function (from Green \& Myerson, 2004) is $V=A /(1+k D)$ ( $k$ is the discounting parameter).

3 . The Green and Myerson (2004) hyperbola-like discounting function is $V=A /(1+k D)^{s}(s$ is the nonlinear scaling parameter of amount and/or time).

4. The McClure, Laibson, Loewenstein, and Cohen (2004) quasihyperbolic function is $V=A * \beta * \delta^{D}$ for $D>0$ ( $\beta$ is the short-term and $\delta$ the long-term discount parameter).

5. Subjects had to complete long sequences of hypothetical choices, out of which, at the end of the experiment, one choice was randomly realized in a gift certificate.

6. Note that this reward delay interval is much shorter than the one in studies using monetary reward, since this is usually delivered at the end of the experiment.

7. More physically, the state space is also called phase space.

8. More physically, collective variables are called order parameters.

9. Practically, this reduction in dimensionality is achieved by performing a principal component analysis on recorded data (e.g., Elman, 2004; Spivey, 2007).

10. Examples are the nonlinear interaction of system elements reflected in the system's attractor layout, bifurcation points, areas of criticality, and hysteresis in the parameter space.

(Manuscript received February 28, 2008; revision accepted for publication August 13, 2008.) 